\title{
Amino Acid Sequence Motifs Essential for P0-Mediated Suppression of RNA Silencing in an Isolate of Potato leafroll virus from Inner Mongolia
}

\author{
Tao Zhuo, Yuan-Yuan Li, Hai-Ying Xiang, Zhan-Yu Wu, Xian-Bin Wang, Ying Wang, Yong-Liang Zhang, \\ Da-Wei Li, Jia-Lin Yu, and Cheng-Gui Han \\ State Key Laboratory for Agro-Biotechnology and Department of Plant Pathology, China Agricultural University, Beijing \\ Submitted 13 August 2013. Accepted 14 January 2014.
}

\begin{abstract}
Polerovirus P0 suppressors of host gene silencing contain a consensus F-box-like motif with Leu/Pro $(\mathrm{L} / \mathrm{P})$ requirements for suppressor activity. The Inner Mongolian Potato leafroll virus (PLRV) $\mathrm{P0}$ protein $\left(\mathrm{PO}^{\mathrm{PL}-\mathrm{IM}}\right)$ has an unusual F-box-like motif that contains a Trp/Gly (W/G) sequence and an additional GW/WG-like motif (G139/W140/G141) that is lacking in other P0 proteins. We used Agrobacterium infiltration-mediated RNA silencing assays to establish that $\mathrm{P0}^{\mathrm{PL}-\mathrm{IM}}$ has a strong suppressor activity. Mutagenesis experiments demonstrated that the $\mathrm{P0}{ }^{\mathrm{PL}-\mathrm{IM}} \mathrm{F}$-box-like motif encompasses amino acids 76-LPRHLHYECLEWGLLCG THP-95, and that the suppressor activity is abolished by L76A, W87A, or G88A substitution. The suppressor activity is also weakened substantially by mutations within the G139/W140/G141 region and is eliminated by a mutation $(\mathrm{F} 220 \mathrm{R})$ in a $\mathrm{C}$-terminal conserved sequence of $\mathrm{P0}^{\mathrm{PL}-\mathrm{IM}}$. As has been observed with other $\mathrm{P0}$ proteins, $\mathrm{P} 0^{\mathrm{PL}-\mathrm{IM}}$ suppression is correlated with reduced accumulation of the host AGO1-silencing complex protein. However, $\mathrm{P0}^{\mathrm{PL}-\mathrm{IM}}$ fails to bind SKP1, which functions in a proteasome pathway that may be involved in AGO1 degradation. These results suggest that $\mathrm{P0}^{\mathrm{PL}-\mathrm{IM}}$ may suppress RNA silencing by using an alternative pathway to target AGO1 for degradation. Our results help improve our understanding of the molecular mechanisms involved in PLRV infection.
\end{abstract}

RNA silencing is an immune mechanism used by hosts to combat viral infections at the nucleic acid level. RNA silencing was first discovered in plants (Lindbo and Dougherty 2005; Napoli et al. 1990), and has subsequently been shown to occur in a variety of eukaryotic organisms, including mammals ( $\mathrm{Li}$ et al. 2013; Maillard et al. 2013). RNA silencing is initiated when double-stranded RNA (dsRNA) triggers Dicer-like enzymatic degradation of RNA transcripts to produce homologous short (21 to 24 nucleotides [nt]) RNAs, called small interfering RNAs (siRNAs) (Baulcombe 2004; Hamilton and Baulcombe 1999). One of the two strands in an siRNA duplex is recruited by an ARGONAUTE (AGO) RNA-binding and slicer protein (Bartel 2004; Elbashir et al. 2001) to form an RNA-induced

Corresponding author: C.-G. Han; E-mail: hanchenggui@cau.edu.cn; Telephone: +8610 62733336; Fax: +861062732012.

* The $\boldsymbol{e}$-Xtra logo stands for "electronic extra" and indicates two supplementary figures are published online.

(C) 2014 The American Phytopathological Society silencing complex (RISC) that targets viral genomic RNAs or messenger RNAs (mRNAs) for degradation (Baumberger and Baulcombe 2005; Ding and Voinnet 2007; Mi et al. 2008; Qi et al. 2005).

To overcome host RNA silencing, numerous viral-encoded suppressor of RNA silencing (VSR) proteins have evolved (Silhavy and Burgyán 2004; Voinnet 2005; Wang et al. 2012). These include more than 35 suppressor families, which have no obvious sequence similarity, that are multifunctional and can act at more than one step in the silencing pathway (Burgyán and Havelda 2011; Csorba et al. 2009). The most common mechanism of VSR action is to mediate sequestration of dssiRNA (Csorba et al. 2007; Ding and Voinnet 2007; Lakatos et al. 2006; Mérai et al. 2006). The best-characterized VSRs employing this strategy are the tombusvirus P19 protein, which binds siRNA duplexes (Lakatos et al. 2006) and the Turnip crinkle virus (TCV) P38 coat protein (CP), which has two suppressor functions, one of which is binding viral dsRNAs of various sizes (Burgyán and Havelda 2011; Deleris et al. 2006; Mérai et al. 2006). Overall, these findings show that RNA binding activities are a central feature of many VSR proteins.

Other suppressor proteins interact with RISC proteins encoded by the host (Csorba et al. 2009; Wang et al. 2012). A classic example of this mechanism is the Cucumber mosaic virus (CMV) $2 \mathrm{~b}$ protein, which binds physically with the host AGO1/AGO4 proteins, at the PAZ domains of these proteins, to specifically inhibit RNA cleavage activities of the proteins (Duan et al. 2012; González et al. 2010; Goto et al. 2007; Hamera et al. 2012; Zhang et al. 2006). Other recent studies have revealed another strategy in which VSR proteins inhibit RISC activities by mimicking glycine/tryptophan (GW/WG) proteins known to interact directly with AGO proteins (Azevedo et al. 2010; Burgyán and Havelda 2011; Giner et al. 2010; Jin and Zhu 2010; Szabó et al. 2012). A prime example of this mechanism is the TCV P38 CP, which contains two essential GW repeats required for binding to Arabidopsis thaliana AGO1 (Azevedo et al. 2010; Burgyán and Havelda 2011). P38 binding is thought to interfere with siRNA loading into AGO1 by interacting preferentially with nonloaded AGO1 without affecting siRNA-loaded AGO1 RISC activities (Azevedo et al. 2010). The Sweet potato mild mottle potyvirus (SPMMV) suppressor (P1) has three N-terminal WG/GW motifs. Sitedirected mutations demonstrate an absolute requirement for each of the motifs for binding to both unloaded AGO1 and siRNA-loaded AGO1 (Burgyán and Havelda 2011; Giner et al. 2010). Interestingly, the P1 protein of the related Sweet potato feathery mottle virus (SPFMV) is a close homologue of SPMMV P1 but has a nonfunctional AGO-binding domain that 
does not elicit a silencing-suppressor activity. However, remodeling of the protein by introduction of two comparable WG/GW motifs from SPMMV converts SPFMV P1 to a silencing suppressor that is able to bind an AGO (Szabó et al. 2012).

The P0 proteins encoded by the $5^{\prime}$-proximal open reading frames (ORF) of several poleroviruses have been shown to suppress RNA silencing. These poleroviruses, which belong to the family Luteoviridae, include Beet mild yellowing virus (BMYV), Cucurbit aphid-borne yellows virus (CABYV), Turnip yellows virus (syn. Beet western yellows virus), Sugarcane yellow leaf virus (ScYLV), Melon aphid-borne yellows virus (MABYV), Wheat yellow dwarf virus GPV isolate, and Cotton leafroll dwarf virus (Delfosse et al. 2013; Han et al. 2010; Kozlowska-Makulska et al. 2010; Liu et al. 2012; Mangwende et al. 2009; Pfeffer et al. 2002). The amino acid sequence identities of these polerovirus P0 proteins are very low, with an average identity value of $37.06 \%$, and their silencing-suppressor activities vary among different virus isolates. The P0 proteins of most BMYV isolates and the $\mathrm{P} 0$ of a Cereal yellow dwarf virus-RPV (CYDV-RPV) isolate from Australia exhibit RNA silencing-suppressor activities (Fusaro et al. 2012; Kozlowska-Makulska et al. 2010) but the P0 proteins of two related BMYV isolates (BMYV-N32 and -26), several Beet chlorosis virus isolates from Europe, and a CYDV-RPV isolate from New York lack suppressor functions (Guilley et al. 2009; Kozlowska-Makulska et al. 2010). However, despite substantial differences in the sequences and silencing activities of these P0 proteins, they all contain conserved F-box-like domains (Pazhouhandeh et al. 2006).

Recently, several isolates related to Potato leafroll virus (PLRV), the type member of the Polerovirus genus, have been described (King et al. 2011). Among these, the amino acid sequence identities of the $\mathrm{P} 0{ }^{\mathrm{PL}}$ proteins of Iranian PLRV isolates are more closely related to those of the European PLRV isolates than to those of the other isolates (Zarghani et al. 2012). Although the P0 protein $\left(\mathrm{PO} 0^{\mathrm{PL}-\mathrm{NL}}\right)$ from a Dutch PLRV isolate is a weak suppressor of RNA silencing (Pfeffer et al. 2002), an Australian PLRV P0 protein ( $\left.\mathrm{P} 0^{\mathrm{PL}-\mathrm{Au}}\right)$ is a stronger suppressor (Fusaro et al. 2012).

The action mechanisms of the P0 proteins are not as well understood as those of the tombusvirus P19, TCV P38, and CMV 2b VSRs, as mentioned above. The P0 protein of $\mathrm{BWYV}\left(\mathrm{P0}{ }^{\mathrm{BW}}\right)$ has been suggested to suppress RNA silencing by inhibiting secondary siRNA production and by targeting AGO1 for degradation (Baumberger et al. 2007; Csorba et al. 2010). However, $\mathrm{P} 0^{\mathrm{BW}}$ appears to carry out these functions without direct AGO1 binding (Burgyan and Havelda 2011). $\mathrm{P}^{\mathrm{BW}}$ and the $\mathrm{P} 0$ protein of $\mathrm{CABYV}\left(\mathrm{P}^{\mathrm{CA}}\right)$ are thought to target AGO1 by means of their F-box-like motifs interacting with proteins belonging to the SCF family of E3-ligase S-phase kinase-related protein-1 (SKP1) components in Nicotiana benthamiana (Pazhouhandeh 2007). However, degradation of AGO1 is insensitive to proteasome inhibitors, suggesting that the proteasome may not be directly involved in AGO1 degradation (Baumberger et al. 2007; Bortolamiol et al. 2007; Pazhouhandeh et al. 2006). Recently, it has been reported that P0-induced AGO1 degradation depends on the autophagy pathway (Derrien et al. 2012). In addition to the F-box-like domain, the C-terminal conserved $\mathrm{P} 0$ sequence has an important role in suppression of RNA silencing (Han et al. 2010) because mutations of aromatic amino acids in the P0 C-terminal sequence of the polerovirus MABYV $\left(\mathrm{P}^{\mathrm{MA}}\right)$ also destroy suppressor activities.

In this study, we demonstrated that the P0 protein from an Inner Mongolian PLRV isolate $\left(\mathrm{P}^{\mathrm{PL}-\mathrm{IM}}\right)$ is a strong suppressor of RNA silencing. We have dissected the sequence of an unusual
F-box-like motif in $\mathrm{P} 0^{\mathrm{PL}-\mathrm{IM}}$ and further shown that, unlike other P0 proteins, the GW sequences within the F-box-like motif are required for suppression of RNA silencing. We also found that residues in a unique GW/WG-like motif (G139/W140/G141) affect suppressor activity, and a single-residue F220 in a C-terminal conserved sequence is essential for suppression. Additional results revealed that expression of the wild-type $\mathrm{P} 0^{\mathrm{PL}-\mathrm{IM}}$ $\left({ }_{\mathrm{WT}} \mathrm{P} 0^{\mathrm{PL}-\mathrm{IM}}\right)$ results in decreased accumulation of AGO1 but that none of the dysfunctional $\mathrm{P} 0^{\mathrm{PL}-\mathrm{IM}}$ mutants that we constructed affects AGO1 accumulation. However, unlike most P0 proteins, $\mathrm{P} 0^{\mathrm{PL}-\mathrm{IM}}$ fails to interact with SKP1, which participates in the proteasome degradation pathway. Therefore, we propose that the degradation of AGO1 may be carried out by an alternative mechanism.

\section{RESULTS}

$\mathrm{PO}^{\mathrm{PL}-\mathrm{IM}}$ is a strong RNA silencing suppressor.

Given that the PLRV P0 ${ }^{\mathrm{PL}-\mathrm{NL}}$ protein is a weak suppressor of RNA silencing (Pfeffer et al. 2002), we tested the ability of ${ }_{\text {wT }} \mathrm{PO}^{\mathrm{PL}-\mathrm{IM}}$ to suppress silencing by using Agrobacterium transient expression systems similar to those previously described (Johansen and Carrington 2001; Ruiz et al. 1998). In our assays, transformed Agrobacterium tumefaciens GV3101 strains harboring either control or suppressor protein genes in the binary vector, pGD, were mixed individually with a GV3101 strain containing pGDG for expression of green fluorescent protein (GFP) (Goodin et al. 2002) and then co-infiltrated into $N$. benthamiana leaves. The suppressor activity of the ${ }_{\mathrm{WT}} \mathrm{P} 0^{\mathrm{PL}-\mathrm{IM}}$ protein expressed from $\mathrm{pGD}$ (pGDP0 ${ }^{\mathrm{PL}-\mathrm{IM}}$ ) was evaluated in the infiltrated leaves in comparison with those of the Tomato bushy stunt virus (TBSV) P19 protein (pGDP19) and of $\mathrm{P} 0^{\mathrm{CA}}\left(\mathrm{pGDP} 0^{\mathrm{CA}}\right)$, which were used as positive controls. The plasmid pGD, which does not express GFP, served as a negative control.

Leaves Agrobacterium-infiltrated (agroinfiltrated) with ${ }_{\text {wT }} \mathrm{PO}^{\mathrm{PL}-\mathrm{IM}}$ expressed a strong GFP fluorescence by 5 days postinfiltration (dpi) that was comparable with the green fluorescence emanating from the leaves infiltrated with P19 and $\mathrm{P} 0^{\mathrm{CA}}$, respectively (Fig. 1A). These results suggest that $\mathrm{P} 0^{\mathrm{PL}-\mathrm{IM}}$ and $\mathrm{PO}^{\mathrm{CA}}$ are as strong suppressors of RNA silencing as TBSV P19. In contrast, GFP fluorescence was negligible in leaves coinfiltrated with agrobacteria harboring pGDG and the empty vector pGD (Fig. 1A). To provide quantitative assessments, Western blot analyses were used to confirm GFP accumulation in sectors co-infiltrated with $\mathrm{pGDG}$ or with ${ }_{\mathrm{WT}} \mathrm{P} 0^{\mathrm{PL}-\mathrm{IM}}, \mathrm{P} 19$, or pGD and the results agreed with the fluorescence levels observed in the infiltrated leaves (data not shown).

\section{The LP motif L76/P77 but not L59/P60 residues \\ in the $\mathrm{F}$-box-like motif of ${ }_{\mathrm{WT}} \mathrm{P0}^{\mathrm{PL}-\mathrm{IM}}$ \\ is required for suppression of RNA silencing.}

Inspection of the $\mathrm{P}^{\mathrm{PL}-\mathrm{IM}}$ sequence revealed that $\mathrm{P} 0^{\mathrm{PL}-\mathrm{IM}}$ has an unusual F-box-like motif residing between residues 59 and 95 that appears to consist of a partial duplication of the consensus F-box-like motif $\left[\mathrm{LPxx}(\mathrm{L} / \mathrm{I}) \mathrm{x}_{10-13} \mathrm{P}\right]$ found in other $\mathrm{P} 0$ proteins and in plant SFC ubiquitin E3 ligase subunits (Pazhouhandeh et al. 2006; Risseeuw et al. 2003). The first region (59LPLLNCKRGRISTSGLQLP-77 [bold indicates landmarks of important motifs]) corresponds to the F-box-like motifs of other polerovirus $\mathrm{P} 0$ proteins, except for residue 63 , which is an $\mathrm{N}$ instead of the consensus L or I residues (Fig. 1B). The second partial overlapping region (76-LPRHLHYECLEWGLLCGTHP95) has an F-box-like motif similar to the consensus F box but harbors a WG sequence reminiscent of the GW/WG motifs found to interact with AGO1 in the CMV 2b and TCV P38 GW/WG residues involved in AGO1 interactions. 
To determine which of the LP residues are essential for $\mathrm{P} 0^{\mathrm{PL}-\mathrm{IM}}$ suppressor activity, we constructed $\mathrm{P} 0^{\mathrm{PL}-\mathrm{IM}}$ L59A/P60A and -L76A/P77A mutant proteins and compared the suppressor activities of these mutants with ${ }_{\mathrm{wT}} \mathrm{P} 0^{\mathrm{PL}-\mathrm{IM}} . N$. benthamiana leaves were co-infiltrated with Agrobacterium derivatives carrying $\mathrm{pGDG}$ and ${ }_{\mathrm{wT}} \mathrm{P} 0^{\mathrm{PL}-\mathrm{IM}}$ or the two $\mathrm{P} 0^{\mathrm{PL}-\mathrm{IM}}$ mutants. P19 and P0 ${ }^{\text {CA }}$ were used as positive controls and the empty binary vector pGD was used as a negative control. At 5 dpi, GFP fluorescence in leaves that had been co-infiltrated with pGDG and P0 carrying the L59A/P60A mutations was very similar to that observed in leaves infiltrated with ${ }_{\mathrm{WT}} \mathrm{P} 0^{\mathrm{PL}-\mathrm{IM}}$ or with P19 and P0 ${ }^{\mathrm{CA}}$ (Fig. 1A). In contrast, GFP fluorescence was not detected in leaves that were co-infiltrated with pGDG and the L76A/P77A double mutant or the pGD negative control (Fig. 1A). We also constructed single L76A and P77A mutations and found that the L76A mutant but not the P77A mutant lost the suppressor activity (Fig. 1A). These results indicate that a functional F-box-like sequence critical for the suppressor function of $\mathrm{P} 0^{\mathrm{PL}-\mathrm{IM}}$ resides between residues $\mathrm{L} 76$ and P95, and that the sequence spanning L59 to P77 does not exhibit F-box-like functions.
Critical residues in two ${ }_{\text {WT }} \mathrm{P0}^{\mathrm{PL}-\mathrm{IM}} \mathrm{WG} / \mathrm{GW}$-like motifs are required for the suppressor activity.

Our sequence comparisons revealed WG/GW-like candidate residues (W87/G88) within the ${ }_{\mathrm{WT}} \mathrm{P} 0^{\mathrm{PL}-\mathrm{IM}} \mathrm{F}$-box-like motif that are not present in other consensus P0 sequences (Fig. 2A). An additional F-box-like sequence downstream of this region encompasses amino acids G139, W140, and G141 (Fig. 2A). To investigate the significance of the $\mathrm{W} / \mathrm{G}$ residues within the $\mathrm{P} 0{ }^{\mathrm{PL}-\mathrm{IM}}$ F-box-like motif for silencing-suppressor activity, we generated single and double W87/G88 mutations by substitutions with alanine residues (Fig. 2A). To increase the uniformity of the experiments, we infiltrated the tips of the leaves with pGDG and the control pGD, the left basal side of the leaves with $\mathrm{pGDG}$ and ${ }_{\mathrm{WT}} \mathrm{P} 0^{\mathrm{PL}-\mathrm{IM}}$, and the right basal side with $\mathrm{pGDG}$ and the mutant $\mathrm{P} 0^{\mathrm{PL}-\mathrm{IM}}$ derivatives (Fig. $2 \mathrm{~B}$, first three upper panels). The results at 5 dpi showed that all sectors infiltrated with the mutant derivatives and with the pGD vector failed to exhibit fluorescence but sectors infiltrated with ${ }_{\mathrm{WT}} \mathrm{P} 0^{\mathrm{PL}-\mathrm{IM}} \mathrm{ex}-$ hibited fluorescence comparable with the p19 control infiltration (Fig. 2B, bottom right panel). An additional double mutant with tryptophan/glycine exchanges was constructed (Fig.
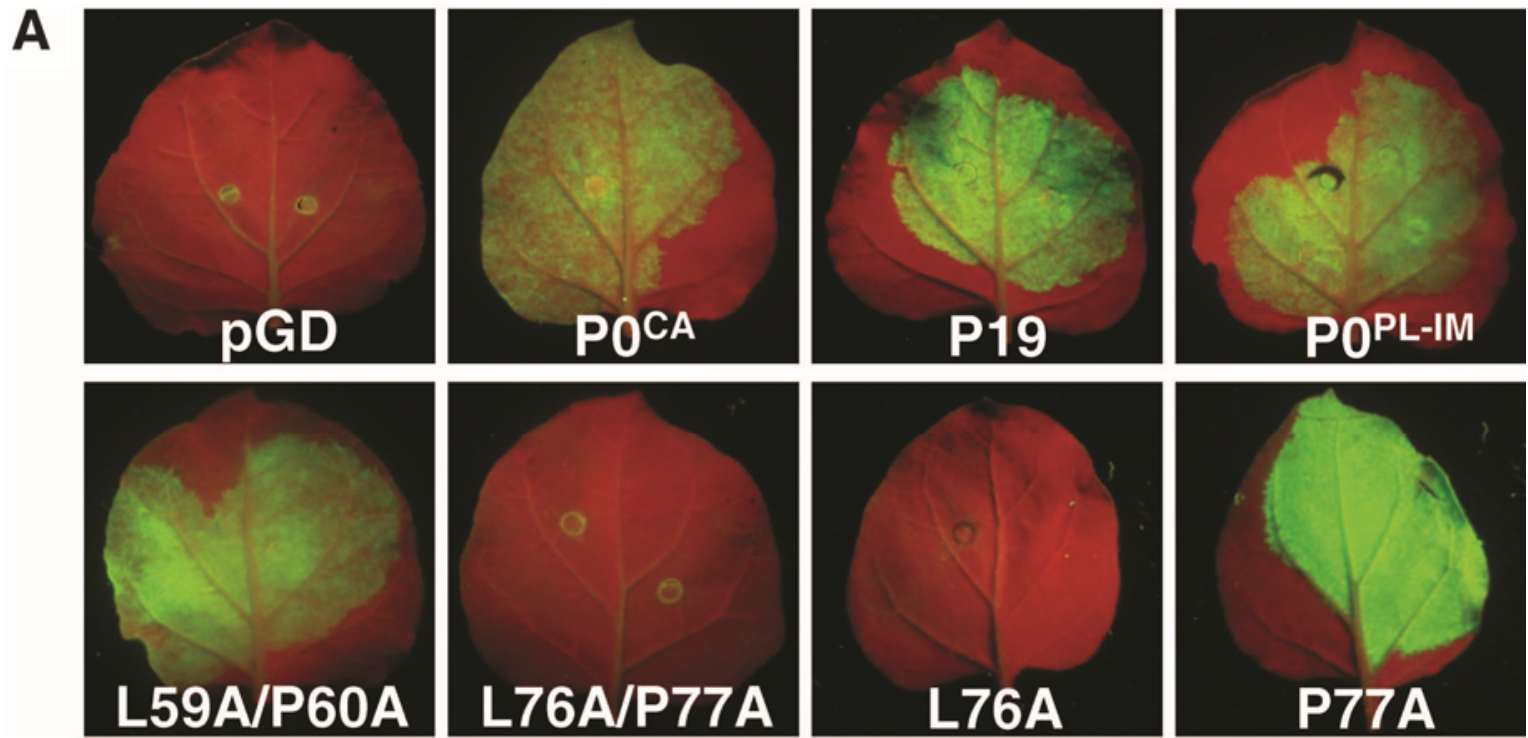

\section{B CABYV : 53 -LPLIIS-EQLS-GDYVYTPGASKRIILARFHRHCGAP- 87 BMYV : 53 -LPLILS-KQLDPGSFIYTPGKRQSLRLARFYNYCGAV- 88 BWYV : 53 -LPLILS-EQLQ-GDFRYVPGRRQRHRLARLHKACGAS- 87 CYDV : 64 -LPILLTGESYSWRGHLNLPLSYTELLVRWGLAVGYFP- 100 MABYV : 56 -LPLIIS-EQLS-GDYVYTPGVARRIMVARFHRHCGAP- 90 PLRV $^{\text {IM }}$ : 59 -LPLLNCKRGRISTSGLQLPRHLHYECLEWGLLCGTHP- 95}
L59A/P60A :
aaLLNCKRGR ISTSGLQLPRHLHYECLEWGLLCGTHP L76A/P77A: L76A: P77A:

\section{LPLLNCKRGRISTSGLOaaRHLHYECLEWGLLCGTHP LPLLNCKRGRISTSGLQ LPLLNCKRGRISTSGLQQLaRHLHYECLEWGLLCGTHP}

Fig. 1. Suppression of local silencing by $\mathrm{P} 0^{\mathrm{PL}-\mathrm{IM}}$ and mutations of the P0 ${ }^{\mathrm{PL}-\mathrm{IM}}$ F-box-like motif to test suppression of RNA silencing. A, Assessment of suppression of gene silencing in Nicotiana benthamiana leaves by co-infiltration of an Agrobacterium strain containing pGDG for expression of green fluorescent protein, plus a strain containing the control pGD plasmid, or strains containing pGD plasmids for expression of P0 ${ }^{\mathrm{CA}}$, P19, P0 ${ }^{\mathrm{PL}-\mathrm{IM}}$, L59A/P60A, L76A/P77A, L76A, or P77A. Photographs were taken of leaves at 5 days postinfiltration under long-wavelength UV light. Designations of the test suppressor proteins are below the leaf photographs. B, Alignment of the conserved sequences of P0 F-box-like domains from six poleroviruses. Two regions (amino acids 59 to 77 and 76 to 95 ) in $\mathrm{PO} 0^{\mathrm{PL}-\mathrm{IM}}$, that are marked by blue and red colors, respectively, have homology to F-box-like domains. All the conserved residues are bold in black. DNAMAN program alignments of the conserved amino acid sequences from GenBank show CABYV (X76931), BMYV (NC003491), BWYV (NC004756), CYDV (NC004751), MABYV (NC010809), and PLRV (KC456052). Alanine substitutions (bold a's) were introduced to generate the L59A/P60A, L76A/P77A, L76A, and P77A P0 ${ }^{\mathrm{PL}-\mathrm{IM}}$ mutants. 
2A) but this mutant was also dysfunctional in silencing suppression (Fig. 2B, upper right panel). Hence, both of the Fbox-like $\mathrm{GW}$ residues are required for $\mathrm{P} 0^{\mathrm{PL}-\mathrm{IM}}$ silencing suppression and the $\mathrm{W} / \mathrm{G}$ residues cannot be exchanged. Thus, our experiments reveal that the W87/G88 residues are critical for suppressor activity and further confirm the importance of the F-box-like domain 76-LPRHLHYECLEWGLLCGTHP-95 for $\mathrm{P} 0^{\mathrm{PL}-\mathrm{IM}}$ suppressor activity.

In the same set of experiments, alanine substitutions for the G139/W140/G141 residues were constructed and additional

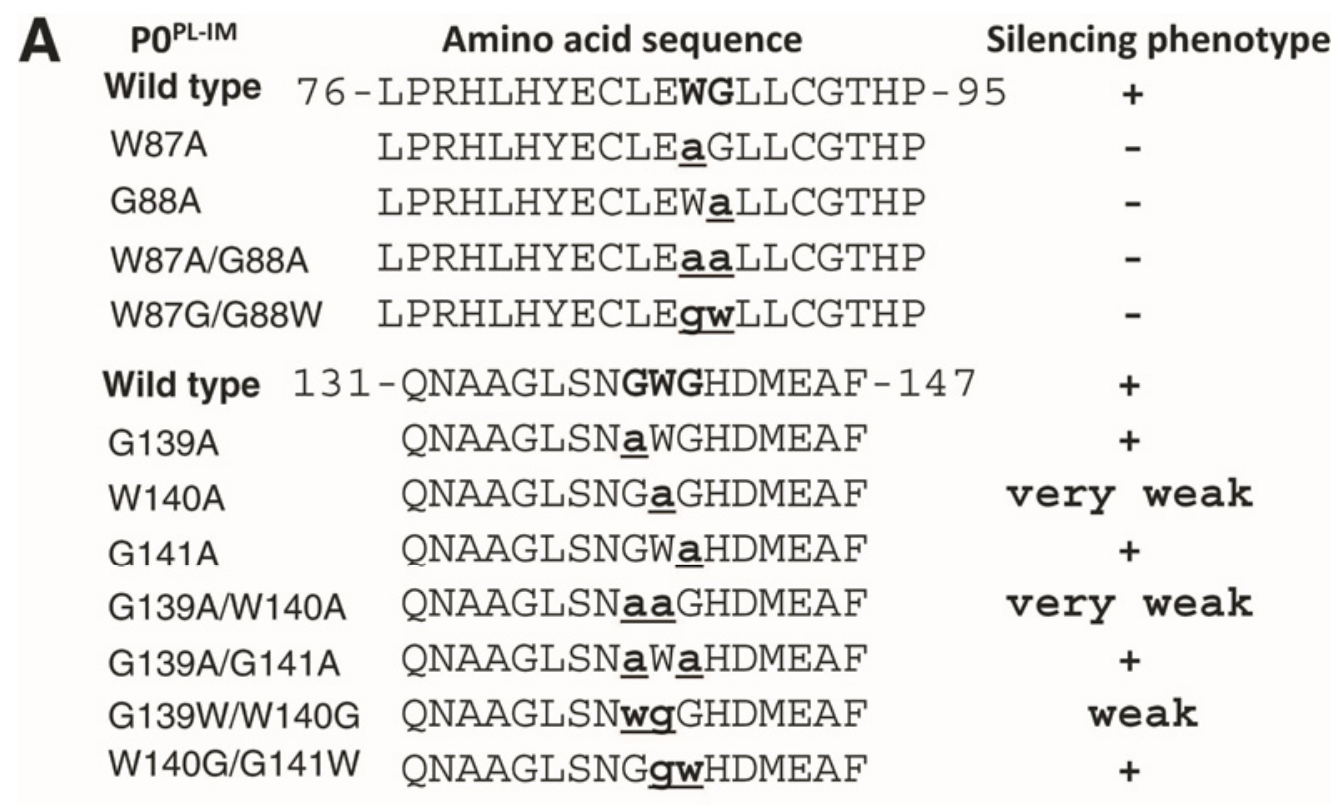
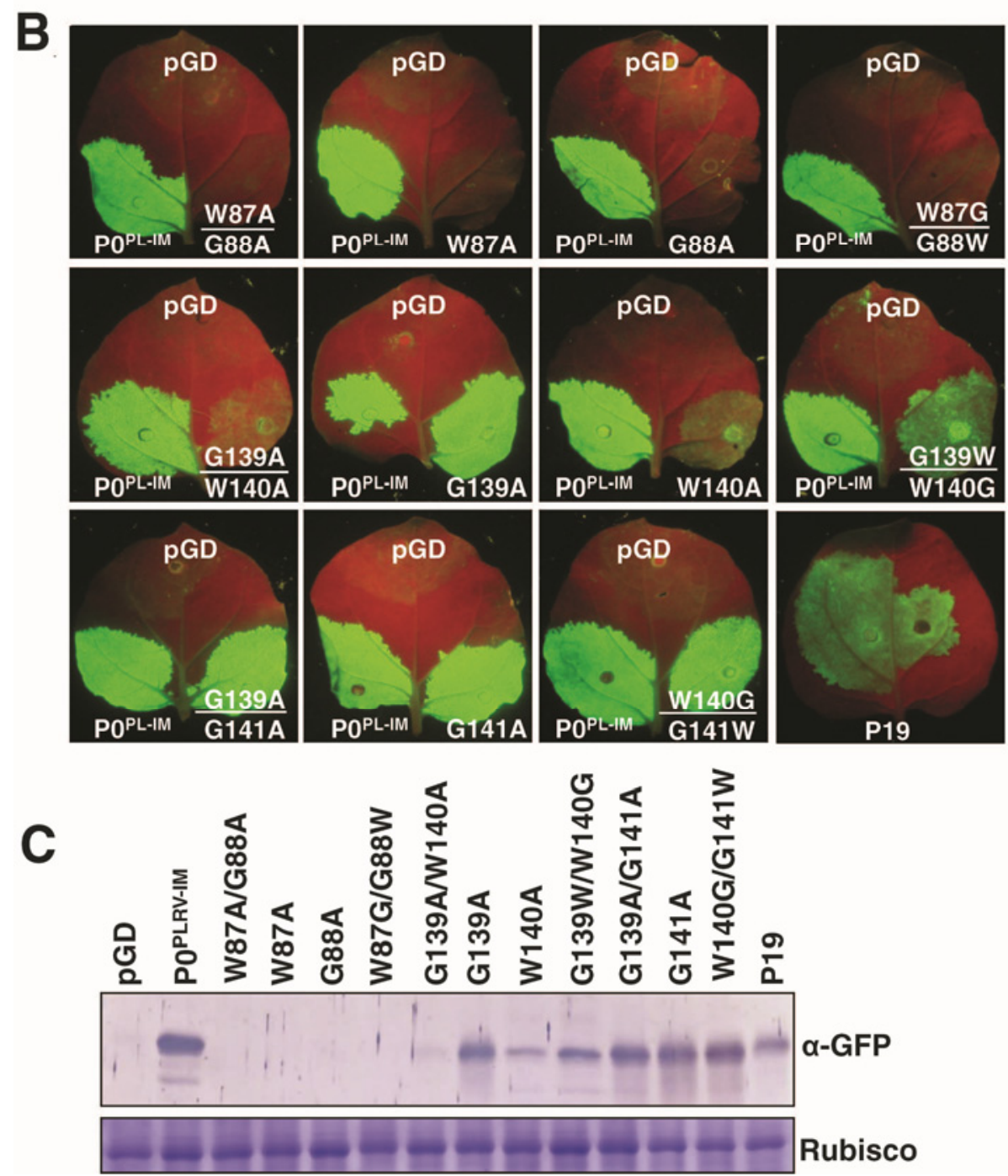
interchanges of the tryptophan and glycine residues were incorporated into $\mathrm{P} 0^{\mathrm{PL}-\mathrm{IM}}$ (Fig. $2 \mathrm{~A}$ ). These mutants and the ${ }_{\mathrm{WT}} \mathrm{P} 0^{\mathrm{PL}-\mathrm{IM}}$ were used in co-infiltration experiments to compare their suppressor activities. GFP fluorescence of the relevant leaf sectors indicated that the G139A and G141A mutants had suppressor activities similar to that of ${ }_{\mathrm{WT}} \mathrm{P} 0^{\mathrm{PL}-\mathrm{IM}}$ but that the $\mathrm{W} 140 \mathrm{~A} \mathrm{mu}-$ tant had greatly reduced GFP fluorescence and, hence, weakened suppressor activity (Fig. 2B). The double mutant G139A/ W140A totally disrupted the suppressor activity, whereas the G139A/G141A mutant retained strong suppressor activity (Fig. 2B). To further evaluate the G/W/G functions, tryptophan and glycine exchanges were tested for suppressor activity. Leaves infiltrated with the G139W/W140G mutant had somewhat weaker visual fluorescence than leaves co-infiltrated with ${ }_{\mathrm{WT}} \mathrm{P} 0^{\mathrm{PL}-\mathrm{IM}}$ but the activity of this mutant seemed to be higher than that of the corresponding W140A and G139A/W140A mutants (Fig. 2B). The GFP accumulation levels in each mutant infiltration experiment were further characterized by Western blotting (Fig. 2C) and, in each case, the GFP accumulation reflected the fluorescence shown in the relevant leaf sectors. The results demonstrate that the G139/W140/G141 signature residues are also essential for suppressor activity of P0 ${ }^{\text {PL-IM }}$.

\section{Defective silencing mutants result \\ in increased siRNA accumulation.}

To further evaluate the above results, we selected ${ }_{\mathrm{WT}} \mathrm{P} 0^{\mathrm{PL}-\mathrm{IM}}$ and representative mutants by tagging a $3 \times$ flag epitope at their $\mathrm{C}$ termini, and used these derivatives for co-infiltrations followed by molecular detection. $N$. benthamiana leaves were coinfiltrated with $\mathrm{pGDG}$ and flag-tagged ${ }_{\mathrm{wT}} \mathrm{P0} 0^{\mathrm{PL}-\mathrm{IM}}$ or its L59A/P60A, L76A/P77A, W87A, W140A, and F220R mutant derivatives. Co-infiltration of $\mathrm{pGDG}$ with $\mathrm{P} 0^{\mathrm{CA}}$ and $\mathrm{P} 19$ served as positive controls. An F220R P0 ${ }^{\mathrm{PL}-\mathrm{IM}}$ mutant corresponding to a conserved motif near the $\mathrm{P} 0^{\mathrm{PL}-\mathrm{IM}} \mathrm{C}$-terminal region was also tested because an F220R mutation in the analogous region of MABYV has been shown to destroy P0 suppressor activity (Han et al. 2010). At 5 dpi, GFP fluorescence had disappeared or declined to very low levels when pGDG was co-infiltrated with flag-tagged L76A/P77A, W87A, W140A, and F220R mutants and the negative pGD control (Fig. 3A). In contrast, GFP fluorescence in leaves infiltrated with the ${ }_{\mathrm{WT}} \mathrm{P} 0^{\mathrm{PL}-\mathrm{IM}}$ and the L59A/P60A derivatives was strong compared with the positive $\mathrm{P} 0{ }^{\mathrm{CA}}$ and $\mathrm{P} 19$ controls, indicating that the flag tag did not compromise silencing-suppressor activities (Fig. 3A).

Total mRNA and protein were then extracted from regions co-infiltrated with the above combinations of constructs. Northern blot analyses revealed that the levels of GFP mRNA were much higher in leaves that expressed GFP plus ${ }_{\mathrm{wT}} \mathrm{P} 0^{\mathrm{PL}-\mathrm{IM}}$, L59A/P60A, P0 ${ }^{\mathrm{CA}}$, or $\mathrm{P} 19$ than in leaves agroinfiltrated with pGD, L76A/P77A, W87A, W140A, or F220R (Fig. 3B). Additional Western blot analyses showed that GFP protein accumulation levels (Fig. 3C) were consistent with GFP fluorescence levels shown in Figure 3A. The levels of GFP protein accumu- lations in leaves co-infiltrated with pGDG and L59A/P60A were similar to those infiltrated with the ${ }_{\mathrm{WT}} \mathrm{P} 0^{\mathrm{PL}-\mathrm{IM}}$ protein and the $\mathrm{P} 0^{\mathrm{CA}}$ and $\mathrm{P} 19$ positive controls (Fig. 3C). However, reductions in GFP protein levels were observed in leaves co-infiltrated with combinations of pGDG and L76A/P77A, W87A, W140A, F220R, or the pGD negative control (Fig. 3C). Hence, the results of the flag-tagged ${ }_{\mathrm{WT}} \mathrm{P} 0^{\mathrm{PL}-\mathrm{IM}}$ proteins (Fig. $3 \mathrm{~A}$ ) are entirely consistent with the results of the untagged ${ }_{\mathrm{WT}} \mathrm{PO} 0^{\mathrm{PL}-\mathrm{IM}}$ derivatives (Figs. $1 \mathrm{~A}$ and $2 \mathrm{~B}$ and $\mathrm{C}$ ).

To test further whether the ${ }_{\mathrm{WT}} \mathrm{P} 0^{\mathrm{PL}-\mathrm{IM}}$ and its mutants affect $G F P$ expression through suppression of RNA silencing, we analyzed the levels of $G F P$-specific siRNAs in all of the treatments described in Figure $3 \mathrm{~A}$. The results clearly revealed that 21- to 24-nt GFP siRNAs accumulated to high levels in leaves infiltrated with pGDG plus pGD, L76A/P77A, W87A, W140A, or F220R (Fig. 3D). The levels of the GFP siRNAs were also consistently lower in leaves infiltrated with pGDG plus ${ }_{\mathrm{WT}} \mathrm{P} 0^{\mathrm{PL}-}$ IM or L59A/P60A (Fig. 3D). These results indicate that the L59A/P60A mutant that retains the suppressor activity and ${ }_{\mathrm{wT}} \mathrm{P} 0^{\mathrm{PL}-\mathrm{IM}}$ effectively block accumulation of GFP siRNAs, whereas expression of the silencing-defective mutants fails to affect the levels of GFP siRNA accumulation.

To ensure that the null mutants were expressed in the infiltrated $N$. benthamiana leaves, accumulations of the flagtagged ${ }_{\mathrm{WT}} \mathrm{P} 0^{\mathrm{PL}-\mathrm{IM}}$ as well as L59A/P60A, L76A/P77A, W87A, and W140A mutant derivatives were examined in the presence or absence of TBSV P19. At 5 days after co-infiltration with P19 and pGDG, leaves expressing flag-tagged ${ }_{\mathrm{WT}} \mathrm{P} 0^{\mathrm{PL}-\mathrm{IM}}$ and the $\mathrm{P} 0^{\mathrm{PL}-\mathrm{IM}}$ derivatives exhibited GFP expression and all $\mathrm{P} 0^{\mathrm{PL}-\mathrm{IM}}$ mutant proteins accumulated to high levels (Fig. 4A). In contrast, in the absence of P19, only leaves co-infiltrated with pGDG and ${ }_{\mathrm{WT}} \mathrm{P} 0^{\mathrm{PL}-\mathrm{IM}}$ or the functional L59A/P60 mutant exhibited accumulations of these proteins as well as GFP fluorescence, and leaves infiltrated with pGDG and the rest of P0 mutants showed only trace amounts of the dysfunctional mutant proteins as well as absence of GFP expression (Fig. 4B). These results indicate that the mutant proteins were expressed to the same extent as ${ }_{\mathrm{WT}} \mathrm{P} 0^{\mathrm{PL}-\mathrm{IM}}$ when silencing was suppressed by P19 and that the inability of the L76A/P77A, W87A, W140A, and F220R mutants resulted from degradation of both the dysfunctional $\mathrm{P} 0^{\mathrm{PL}-\mathrm{IM}}$ mutants and GFP by 5 dpi.

\section{P0 ${ }^{\text {PL-IM }}$ silencing activity \\ is correlated with reduced AGO1 accumulation.}

In order to test the effects of $\mathrm{P} 0^{\mathrm{PL}-\mathrm{IM}}$ on $\mathrm{AGO} 1$ accumulation, a $6 \times$ myc-tagged version of Arabidopsis thaliana AGO1 (6myc-AtAGO1, a gift from $\mathrm{H}$. Guo) was introduced into $N$. benthamiana leaves by infiltration with the $3 \times$ flag-tagged ${ }_{\mathrm{wT}} \mathrm{P} 0^{\mathrm{PL}-\mathrm{IM}}$ or ${ }_{\mathrm{WT}} \mathrm{P} 0^{\mathrm{PL}-\mathrm{IM}}$ mutant derivatives or the $\mathrm{pGD}$ control vector. At $4 \mathrm{dpi}$, extracts from co-infiltrated leaves were analyzed by Western blotting. No effects on 6myc-AtAGO1 accumulation were observed when the silencing-suppression-defective mutants (L76A/P77A, W87A, W140A, and F220R) were used, even though the mutant proteins accumulated to normal

Fig. 2. Mutations in the WG/GW-like motifs of $\mathrm{P} 0^{\mathrm{PL}-\mathrm{IM}}$ for suppression tests of RNA silencing. A, Positions of WG/GW signatures within the $\mathrm{P} 0^{\mathrm{PL}-\mathrm{IM}}$ sequence are highlighted in bold uppercase letters and the substitution mutations are indicated by bold lowercase letters representing alanine (a), tryptophan $(\underline{\mathrm{w}})$, or glycine $(\mathrm{g})$ residues. The silencing phenotype of the infiltrated leaves is indicated on the right. B, Co-infiltration of Nicotiana benthamiana leaves to test $\mathrm{P} 0{ }^{\mathrm{PL}-\mathrm{IM}}$ mutants. The first 11 leaves were infiltrated at the top of the leaf with Agrobacterium harboring pGDG plus the control pGD plasmid. As expect, the infiltrated regions fail to fluorescence. The bottom left side of the leaves was infiltrated with pGDG plus pGDP0 $0^{\mathrm{PL}-\mathrm{IM}}$ for expression of green fluorescent protein (GFP) and $\mathrm{P} \mathrm{P}^{\mathrm{PL}-\mathrm{IM}}$. The bottom right side of these leaves shows pGDG plus pGD plasmids for expression of GFP and the mutant proteins W87A/G88A, W87A, G88A, W87G/G88W, G139A/W140A, G139A, W140A, G139W/W140G, G139A/G141A, G141A, or W140G/G141W. Individual infiltrated derivatives are illustrated on the leaves and double mutants are separated by a vertical line. The bottom right leaf shows a P19 positive suppressor control. Photographs were taken of leaves at 5 days postinfiltration under long-wavelength UV light. C, Western blot analyses using GFP polyclonal antiserum $(\alpha$-GFP). Total proteins were extracted from the agro-infiltrated regions for sodium dodecyl sulfate polyacrylamide gel electrophoresis. The loading control was Rubisco stained with Coomassie blue. 
levels when P19 was included to avoid silencing of the exogenous transcripts during the transient assays (Fig. 5). However, it was striking that co-expression of ${ }_{\mathrm{WT}} \mathrm{P} 0^{\mathrm{PL}-\mathrm{IM}}$ and the functional L59A/P60A mutant induced a substantial reduction in the levels of 6myc-AtAGO1 (Fig. 5). This demonstrates that one of the $\mathrm{P} 0{ }^{\mathrm{PL}-\mathrm{IM}}$ silencing-suppressor functions was to trigger destabilization of AGO1.

\section{$\mathrm{P0}^{\mathrm{PL}-\mathrm{IM}}$ fails to interact with $N$. benthamiana SKP1 (NbSKP1) in yeast and in plants.}

As shown above, $\mathrm{P} 0^{\mathrm{PL}-\mathrm{IM}}$ contains an F-box-like motif that is required for silencing-suppression activity. Moreover, the L76/P77 residues represent the two most highly conserved amino acids in the consensus sequence of plant F-box motifs $\left[\mathrm{LPxx}(\mathrm{L} / \mathrm{I}) \mathrm{x}_{10-13} \mathrm{P}\right]$, and the L76A/P77A mutant has negligible suppressor activity. To investigate the activity of $\mathrm{PO} 0^{\mathrm{PL}-\mathrm{IM}}$ in more detail, a yeast two-hybrid system was used to probe interactions between $\mathrm{P} 0^{\mathrm{PL}-\mathrm{IM}}$ and $\mathrm{NbSKP} 1$. SKP1 functions in a proteasome pathway that may be involved in AGO1 degradation. The ORF of ${ }_{\mathrm{WT}} \mathrm{P} 0^{\mathrm{PL}-\mathrm{IM}}$ and $\mathrm{NbSKP} 1$ were amplified and cloned into pGBKT7 and pGADT7, respectively. The resulting plasmid $\mathrm{pGBK}-\mathrm{P} 0^{\mathrm{PL}-\mathrm{IM}}$ was transformed into the yeast strain Y187 and pGAD-NbSKP1 was transformed into the yeast strain AH109 to implement a powerful yeast two-hybrid mating strategy. The combinations pGBKT7/pGADT7, pGBKT7/ pGAD-NbSKP1, pGBK-P0 ${ }^{\mathrm{PL}-\mathrm{IM}} / \mathrm{pGADT}$, and pGBK-P0 ${ }^{\mathrm{MA}} /$ pGADT7 were used as negative controls, and $\mathrm{pGBK}-\mathrm{P} 0^{\mathrm{MA}}$ / pGAD-NbSKP1 provided a positive control. Mixing of the Y187 and AH109 transformants resulted in vigorous growth on agar plates containing synthetic dropout (SD) media lacking leucine and tryptophan (SD/-Leu/-Trp) (Fig. 6A). However, only the diploid yeast strains derived from mating of the positive-control combination $\mathrm{pGBK}-\mathrm{P0} 0^{\mathrm{MA}}$ in $\mathrm{Y} 187$ and $\mathrm{pGAD}$ NbSKP1 in AH109 could grow on the SD media lacking leucine, tryptophan, adenine, and histidine (SD/-Leu/-Trp/-Ade/ -His) that contained X-gal (5-bromo-4-chloro-3-indolyl- $\beta$-Dgalactoside) and expressed $\beta$-galactosidase activity (Fig. 6A). The results demonstrate that $\mathrm{P} 0^{\mathrm{MA}}$ and $\mathrm{P} 0^{\mathrm{PL}-\mathrm{IM}}$ differ in that $\mathrm{P}^{\mathrm{PL}-\mathrm{IM}}$ does not interact with NbSKP1 in yeast. $\mathrm{P} 0^{\mathrm{PL}-\mathrm{IM}}$ also differs from $\mathrm{P} 0^{\mathrm{PL}-\mathrm{NL}}$, which binds $\mathrm{NbSKP} 1$ with a low affinity (Pazhouhandeh 2007).

To use an alternative approach to test interactions between $\mathrm{P} 0^{\mathrm{PL}-\mathrm{IM}}$ and $\mathrm{NbSKP} 1$, we performed a bimolecular fluorescence complementation (BiFC) assay (Walter et al. 2004). The cDNAs that encode P0 ${ }^{\mathrm{PL}-\mathrm{IM}}$ and $\mathrm{NbSKP} 1$ were cloned into the BiFC transformation vectors pSPYNE-35S and pSPYCE-35S to generate plasmids $\mathrm{P} 0^{\mathrm{PL}-\mathrm{IM}}-\mathrm{YN}, \mathrm{P} 0^{\mathrm{PL}-\mathrm{IM}}-\mathrm{YC}, \mathrm{NbSKP1-YN}$, and NbSKP1-YC. Leaves of $N$. benthamiana co-infiltrated with Agrobacterium tumefaciens EHA105 strains harboring the $\mathrm{P} 0^{\mathrm{PL}-\mathrm{IM}}-\mathrm{YN}+\mathrm{NbSKP} 1-\mathrm{YC}$ and NbSKP1-YN+P0 $0^{\mathrm{PL}-\mathrm{IM}}-\mathrm{YC}$ combinations were used to test possible $\mathrm{P} 0^{\mathrm{PL}-\mathrm{IM}}$ interactions with NbSKP1. The P0 ${ }^{\text {ScYLV }}-\mathrm{YN}+\mathrm{NbSKP} 1-\mathrm{YC}$ and the $\gamma \mathrm{b}-\mathrm{YN}+\gamma b-$ $\mathrm{YC}$ combinations served as positive controls, and the $\mathrm{P}^{\mathrm{ScYLV}}$ $\mathrm{YN}+\mathrm{YC}$ combination provided a negative control. No fluorescence was observed in $N$. benthamiana leaf epidermal cells co-infiltrated with $\mathrm{P}^{\mathrm{PL}-\mathrm{IM}}-\mathrm{YN}+\mathrm{NbSKP} 1-\mathrm{YC}$ or NbSKP1-
$\mathrm{YN}+\mathrm{P0} 0^{\mathrm{PL}-\mathrm{IM}}-\mathrm{YC}$ (Fig. 6B). Likewise, fluorescence could not be visualized in the negative control combination, although yellow fluorescent protein (YFP) fluorescence was observed in the positive controls (Fig. 6B). In addition, "silencing on the spot" Agrobacterium assays (Johansen and Carrington 2001) revealed that the $\mathrm{P} 0$ constructs tagged for $\mathrm{BiFC}\left(\mathrm{P} 0^{\mathrm{PL}-\mathrm{IM}}-\mathrm{YN}\right.$ and $\left.\mathrm{P} 0^{\mathrm{PL}-\mathrm{IM}}-\mathrm{YC}\right)$ are functional because they retained suppressor activities (Supplementary Fig. S1). Therefore, our data demonstrate that $\mathrm{P} 0^{\mathrm{PL}-\mathrm{IM}}$ fails to interact with $\mathrm{NbSKP} 1$ in either yeast or plants.

\section{DISCUSSION}

Our agroinfiltration results have demonstrated that $\mathrm{P} 0^{\mathrm{PL}-\mathrm{IM}}$ is a strong suppressor of gene silencing and our mutagenesis experiments show that the $\mathrm{P} 0^{\mathrm{PL}-\mathrm{IM}} \mathrm{F}$-box-like domain is required for RNA silencing suppression, as is also the case with previous reports of other P0 proteins (Fusaro et al. 2012; Han et al. 2010; Pazhouhandeh et al. 2006). However, alignment of the amino acid sequences of several P0 proteins reveals that P0 ${ }^{\mathrm{PL}-\mathrm{IM}}$ is unusual because it has two partially overlapping LP motifs. The sequence 59-LPLLNCKRGRISTSGLQLP-77 appears to be an imperfect F-box-like sequence because it lacks a conserved L or I residue at position 63 (Fig. 1B). The sequence 76-LPRHLHYECLEWGLLCGTHP-95 contains an L80 residue and, hence, has a sequence composition consistent with consensus sequences in the F-box-like motifs of other P0 proteins (Fig. 1B). The comparisons also show that the $\mathrm{P} 0^{\mathrm{PL}-\mathrm{IM}}$ region encompassing residues 76 to 95 can be distinguished from other P0 F-box-like motifs by the presence of the W87G88 sequence.

Substitutions of the conserved LP residues with A residues at positions 76 and 77 abolished the suppressor functions, although the same substitutions at residues 59 and 60 did not affect suppressor activity. Interestingly, Pea enation mosaic virus-1 $\mathrm{P0}\left(\mathrm{P0}{ }^{\mathrm{PE}}\right)$, the type member of the Enamovirus genus in the Luteoviridae family, contains a silencing-suppressor protein with an F-box-like domain at positions 124 to 143 amino acids (Fusaro et al. 2012). In the case of $\mathrm{P}^{\mathrm{PE}}$, mutations resulting in changes of amino acids L124, P125, and P143 to A residues abolished suppressor activities, whereas the L124 and P125 double mutations to A residues, plus a single mutation of P143 to an A residue, failed to suppress RNA silencing (Fusaro et al. 2012). In contrast, the $P 0^{\text {PL-IM }}$ L76A mutation but not the P77A mutation destroyed the suppressor activity (Fig. 1A). These results show that $\mathrm{P} 0^{\mathrm{PL}-\mathrm{IM}}$ residues 76-LPRHLHYECLE WGLLCGTHP-95 compose a functional F-box-like motif, and that the L76/P77 residues are essential for the silencing-suppressor activity.

It has been proposed that some silencing suppressors mimic proteins that contain GW/WG repeats that sequester AGO proteins and suppress RNA silencing by preventing siRNA loading into AGO complexes (Jin and Zhu 2010). In our experiments, both of the W87/G88 residues were critical for suppressor function because neither of the amino acids could be substituted for A residues, nor could the $\mathrm{G}$ and $\mathrm{W}$ residues be interchanged

Fig. 3. Abilities of positive and negative controls and representative $\mathrm{P} 0^{\mathrm{PL}-\mathrm{IM}}$ mutants to suppress gene silencing in Nicotiana benthamiana leaves. A, Agroinfiltration of leaves with pGDG plus 1 , the control pGD plasmid or pGD plasmids for expression of $3 \times$ flag tagged 2, P0 ${ }^{\mathrm{PL}-I M}$; 3, L59A/P60A; 4, L76A/P77A; 5, W87A; 6, W140A; or 7, F220R P0 ${ }^{\mathrm{PL}-\mathrm{IM}}$ mutants; and 8, $0^{\mathrm{CA}}$; or 9, P19. Double mutants are separated by a diagonal line. Photographs were taken of leaves at 5 days postinfiltration under long-wavelength UV light. B, Northern blot analysis of high-molecular-weight RNA extracted from the agroinfiltrated regions. Blots were hybridized with probes specific for green fluorescent protein (GFP) mRNA. Ethidium-bromide-stained 28S rRNA was used as an RNA loading control. C, Western blot analysis using GFP polyclonal antiserum. Total proteins were extracted from the agro-infiltrated regions for sodium dodecyl sulfate polyacrylamide gel electrophoresis. The loading control was Rubisco stained with Coomassie blue. D, Northern blot analysis of siRNAs hybridized with a population of heterogeneous GFP probes that had been labeled with $\alpha{ }^{32} \mathrm{P}$ UTP. Ethidium-bromide-stained transfer RNA (tRNA) was used as an RNA loading control. Numbers of the bottom of B, C, and D correspond to extracts from the infiltrated leaves. 


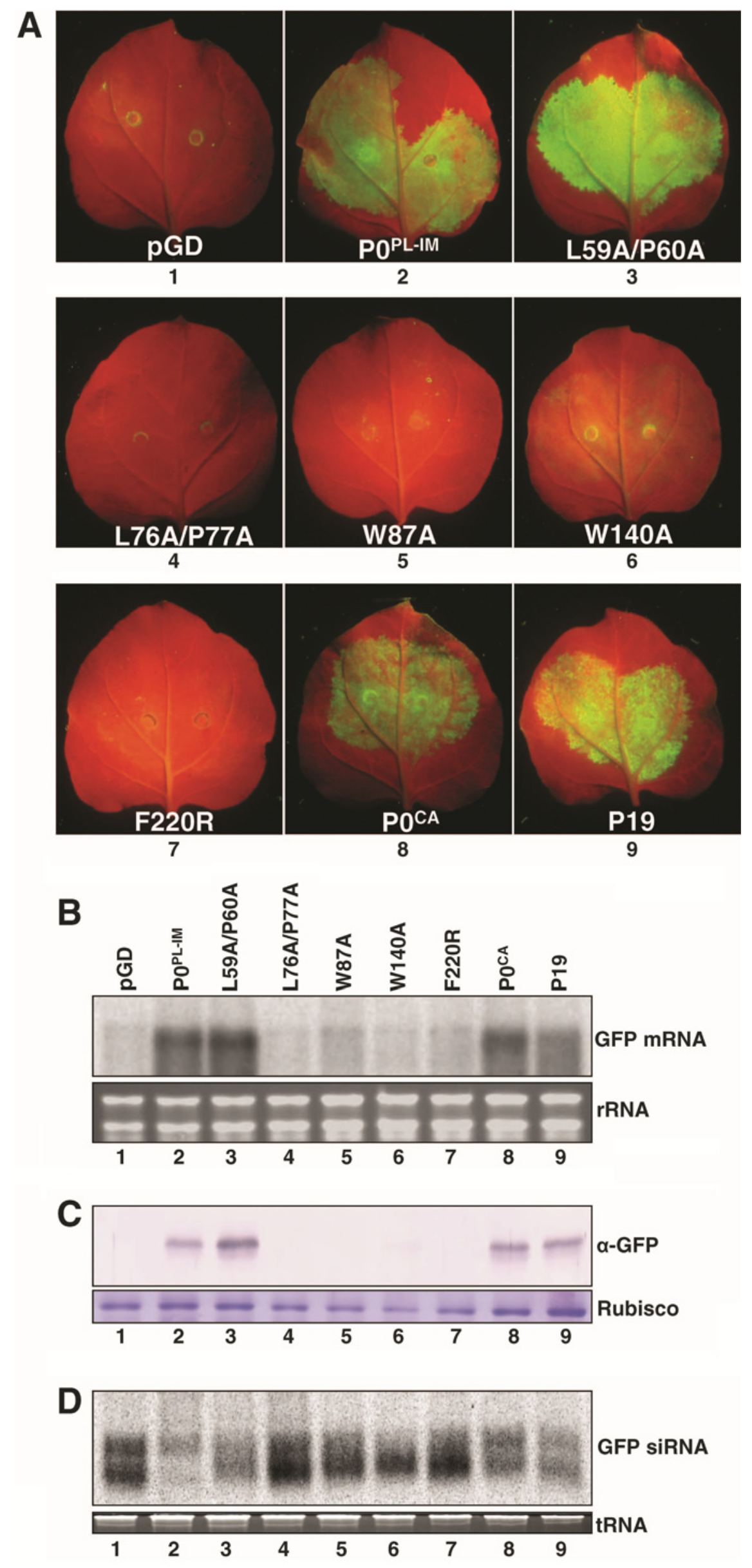


without loss of RNA silencing-suppressor activity (Fig. 2B). Interestingly, no discernible effects on silencing were observed when either or both of the two G residues in the G139/W140/ G141 motif were substituted with A residues, or when mutants in which the GWG residues were replaced by WGG or GGW; however, replacement of GWG with GAG reduced suppressor activity substantially compared with the activity of ${ }_{\mathrm{WT}} \mathrm{P} 0^{\mathrm{PL}-\mathrm{IM}}$ (Fig. 2B). These results suggest that both of the GW/WG-like sequences have characteristics typical of GW/WG motifs and, possibly, may participate in $\mathrm{P}^{\mathrm{PL}-\mathrm{IM}}$-binding activities with other proteins. Moreover, it is possible that $\mathrm{P} 0^{\mathrm{PL}-\mathrm{IM}}$ could be multifunctional and participate in more than one suppressorrelated activity. The location of W87/G88 within the boundary of the $\mathrm{P} 0^{\mathrm{PL}-\mathrm{IM}} \mathrm{F}$-box-like domain (76-LPRHLHYECLEWGL LCGTHP-95) is unusual for P0 proteins, and it is possible that W87/G88 residues may impact $\mathrm{P} 0{ }^{\mathrm{PL}-\mathrm{IM}}$ protein silencing by eliciting conformational changes in the protein or by confer- ring interactions with other proteins. Alignments comparing $\mathrm{P} 0{ }^{\mathrm{PL}-\mathrm{IM}}$ with the $\mathrm{P} 0$ proteins of different PLRV isolates reveal that the 76-LPRHLHYECLEWGLLCGTHP-95 and G139/ W140/G141 motifs, as well as the F220 residue, are highly conserved. In addition, the more distantly related $\mathrm{P} 0{ }^{\mathrm{PL}}$ protein, which is essential for virus accumulation (Sadowy et al. 2001), also shares conservation with the $\mathrm{P} 0$ suppressor proteins in these three regions. Thus, all three regions appear to have been selected during evolution to enable viruses encoding P0-like proteins to infect plants efficiently.

AGO1, as a key component of RISC, not only binds to siRNAs but also has RNA slicer activity (Ding 2010; Hutvagner and Simard 2008; Vaucheret 2008). Our research has identified amino acid substitution mutants that have lost the ability to destabilize AGO1, and these mutants affect the Fbox-like domain (L76A/P77A and W87A), the WG-like motif (W140A), and the C-terminal conserved sequence (F220R)
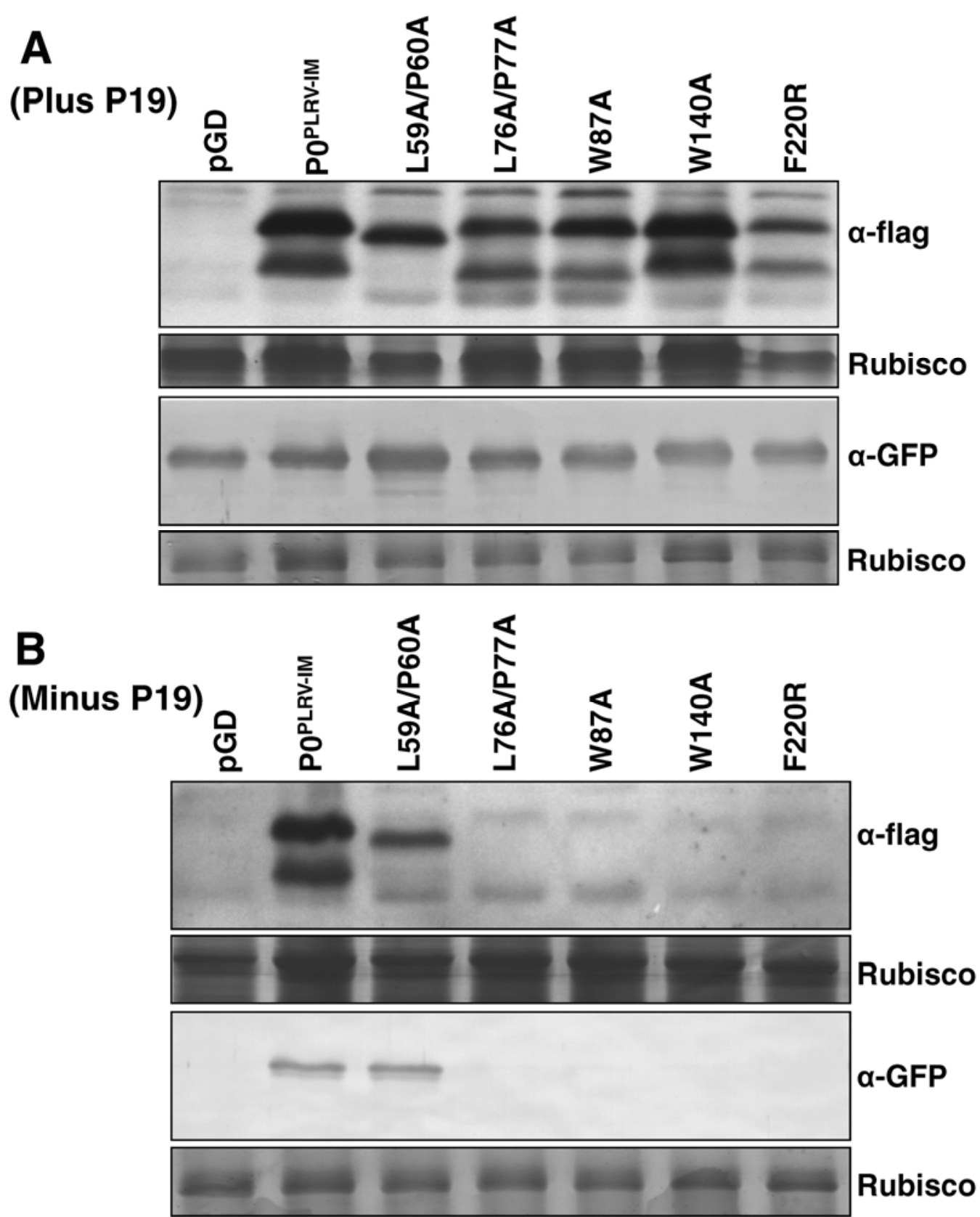

Fig. 4. Accumulation of $3 \times$ flag-tagged $\mathrm{P} 0^{\mathrm{PL}-\mathrm{IM}}$ and $\mathrm{P} 0^{\mathrm{PL}-\mathrm{IM}}$ mutant derivatives in infiltrated tissue at 5 days postinfiltration in the presence or absence of the P19 protein. Western blot analysis using GFP polyclonal antiserum. Total proteins were extracted from the agro-infiltrated regions for sodium dodecyl sulfate polyacrylamide gel electrophoresis. The loading control was Rubisco stained with Coomassie blue. GFP = green fluorescent protein. A, Plus P19. B, Minus P19. 
amino acids. Our finding that $\mathrm{P} 0^{\mathrm{PL}-\mathrm{IM}}$ reduces $\mathrm{AGO} 1$ protein accumulation supports previous reports that $\mathrm{P} 0^{\mathrm{BW}}$ and $\mathrm{P} 0^{\mathrm{PE}}$ can lead to AGO protein degradation (Baumberger et al. 2007; Bortolamiol et al. 2007; Csorba et al. 2010; Fusaro et al. 2012). Given that a direct physical interaction between $\mathrm{PO}^{\mathrm{BW} / \mathrm{CA}}$ and $\mathrm{AGO} 1$ was reported in in vitro pull-down and BiFC analyses (Bortolamiol et al. 2007), we tested potential interactions between $\mathrm{P} 0{ }^{\mathrm{PL}-\mathrm{IM}}$ and $\mathrm{AGO} 1$ by co-immunoprecitation and $\mathrm{BiFC}$ analyses. However, our failure to co-immunoprecipitate $3 \times$ flag-tagged $\mathrm{P} 0{ }^{\mathrm{PL}-\mathrm{IM}}-6 \times$ myc-tagged AGO1 complexes with affinity beads is consistent with a previous report that the $\mathrm{PO}^{\mathrm{BW}}$ protein is not present in RISC fractions that contain the AGO1 complex (Csorba et al. 2010). In addition, our BiFC analyses clearly suggest that $\mathrm{P} 0^{\mathrm{PL}-\mathrm{IM}}$ fails to interact with AtAGO1 (Supplementary Fig. S2). This implies that P0 may affect the stability of AGO1 indirectly, perhaps through targeting another protein that might normally be able to bind AGO1 or stabilize the protein.

We also have provided evidence suggesting that AGO1 is not degraded by the normal SKP1 proteasome pathway (Baumberger et al. 2007; Csorba et al. 2010). The ASK1 protein and its close homolog ASK2 (the most important component of the SCF complex) are the most abundant of the 21 ASK proteins in Arabidopsis thaliana. Each of them can interact with multiple F-box domains (Farrás et al. 2001; Gagne et al. 2002; Risseeuw et al. 2003). The efficiency with which P0 ${ }^{\text {PL-NL }}$ interacts with $\mathrm{NbSKP1}$ is much lower than those of the $\mathrm{P} 0^{\mathrm{CA}}$ or $\mathrm{P}^{\mathrm{BW}}$ protein interactions with $\mathrm{ASK} 1, \mathrm{ASK} 2$, or NbSKP1 (Pazhouhandeh 2007). In contrast, our yeast two-hybrid and $\mathrm{BiFC}$ results indicate that $\mathrm{P} 0^{\mathrm{PL}-\mathrm{IM}}$ does not interact with NbSKP1 (Fig. 6). This implies that the destabilizing effects of P0 on AGO1 accumulation may not require ubiquitination by an SCF-type E3 ligase. This possibility is consistent with previous reports that polyubiquitination and $\mathrm{P}^{\mathrm{BW}}$-mediated AGO1 degradation may be uncoupled (Baumberger et al. 2007;
Csorba et al. 2010). Moreover, it has been suggested recently that AGO1 can be degraded by autophagy without forming a $\mathrm{P}^{\mathrm{BW}}$ complex with SCF E3 ligase, and that $\mathrm{P} 0$ is able to promote AGO1 degradation by autophagy (Derrien et al. 2012). However, we cannot eliminate the possibility that $\mathrm{P} 0^{\mathrm{PL}-\mathrm{IM}}$ may interact with other SKP-related proteins, or that $\mathrm{P} 0^{\mathrm{PL}-\mathrm{IM}}$ interacts with SKP1 during viral infection.

Finally, to the best of our knowledge, our studies with $\mathrm{P} 0^{\mathrm{PL}-\mathrm{IM}}$ are the first report of a polerovirus P0 in which GW/WG-like motifs are required for suppression of RNA silencing. All mutations of the L76/P77, W87, W140, and F220 positions affect the ability of $\mathrm{P} 0^{\mathrm{PL}-\mathrm{IM}}$ to function as an RNA silencing suppressor and to reduce AGO1 accumulation. Although L76A/P77A and W87A affect the F-box-like motif, W140A affects the GW/WG-like motif and F220R interferes with a C-terminal conserved sequence. The mechanisms whereby these mutations affect suppressor functions are not yet clear. A simple possibility is that conformation changes caused by the mutations might decrease P0 activity but we believe it is more likely that the mutations result in interference with a major function targeting AGO1 accumulation.

In summary, our results underscore the diversity of mechanisms for polerovirus $\mathrm{P} 0$ proteins to function as RNA silencing suppressors, and contribute to our understanding of viral suppression of RNA silencing and the molecular mechanisms involved in the PLRV infection. However, much more remains to be determined about whether or how these different motifs or amino acids interact collaboratively or independently to suppress RNA silencing. Additional experiments will need to address whether $\mathrm{P} 0^{\mathrm{PL}-\mathrm{IM}}$ interacts physically with other AGOs, other SKP-like proteins, or other proteins that affect the silencing machinery. Moreover, the crystal structure of $\mathrm{P} 0^{\mathrm{PL}-\mathrm{IM}}$ may provide a more detailed mechanistic explanation as to how these important motifs and conserved amino acids affect suppression of RNA silencing.

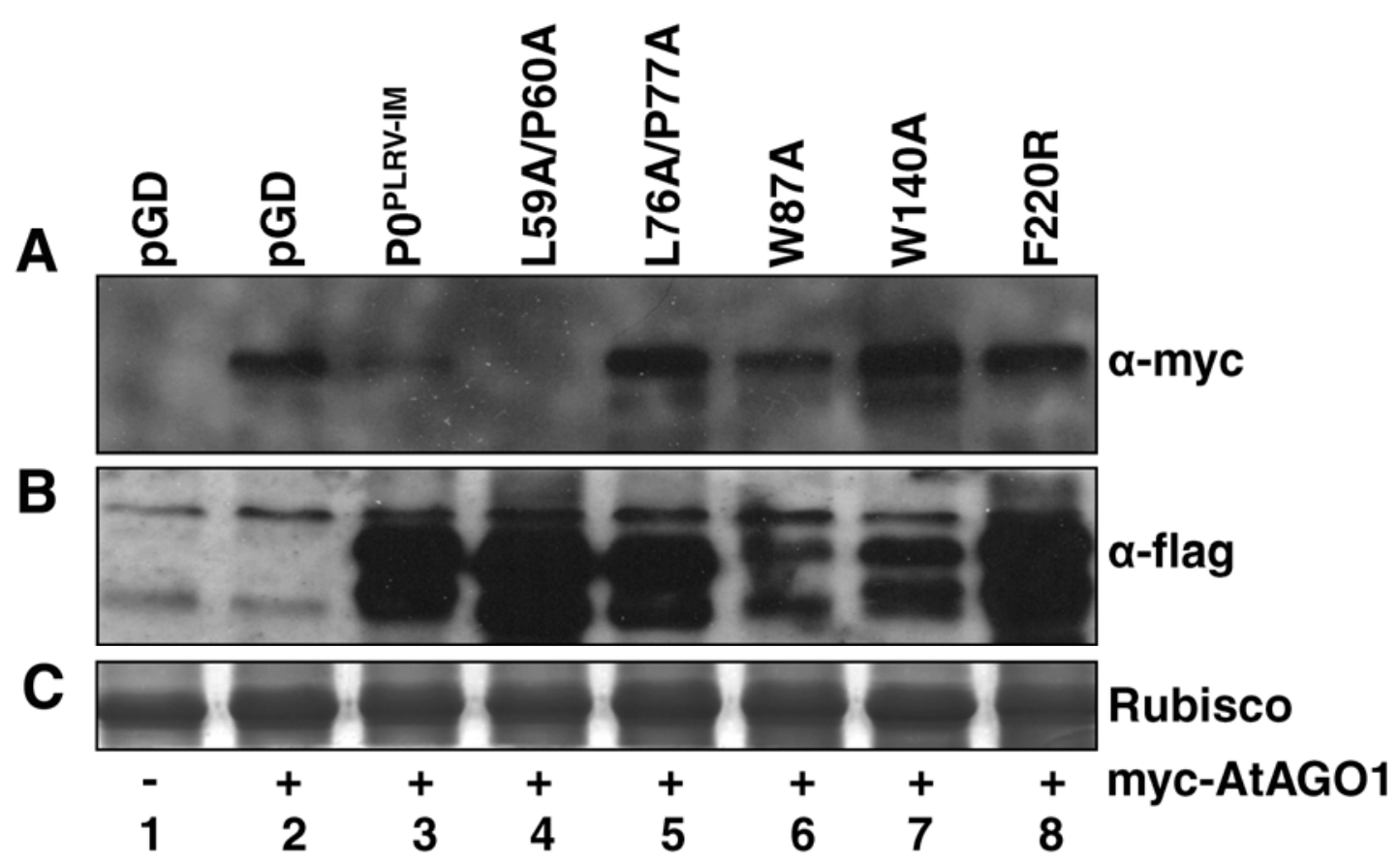

Fig. 5. Effects of $\mathrm{P} \mathrm{P}^{\mathrm{PL}-\mathrm{IM}}$ and mutant derivatives on AGO1 accumulation. Nicotiana benthamiana leaves were co-infiltrated with $6 \times$ myc-tagged AtAGO1,

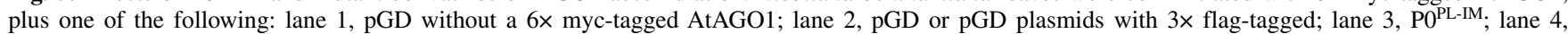
L59A/P60A; lane 5, L76A/P77A; lane 6, W87A; lane 7, W140A; or lane 8, F220R. Western blot analysis using GFP polyclonal antiserum. Total proteins were extracted from the agro-infiltrated regions for sodium dodecyl sulfate polyacrylamide gel electrophoresis. The loading control was Rubisco stained with Coomassie blue. Western blots of total protein extracts were probed at 4 days postinfiltration with anti-myc antibodies $(\alpha-m y c)$ to detect 6 myc-AtAGO1 or anti-flag antibodies $\left(\alpha\right.$-flag) to detect expression of flag tagged $\mathrm{P} 0^{\mathrm{PL}-\mathrm{IM}}$ or $\mathrm{P} 0^{\mathrm{PL}-\mathrm{IM}}$ mutant derivatives, as indicated on the right. Co-infiltrations were performed in the presence of P19. 

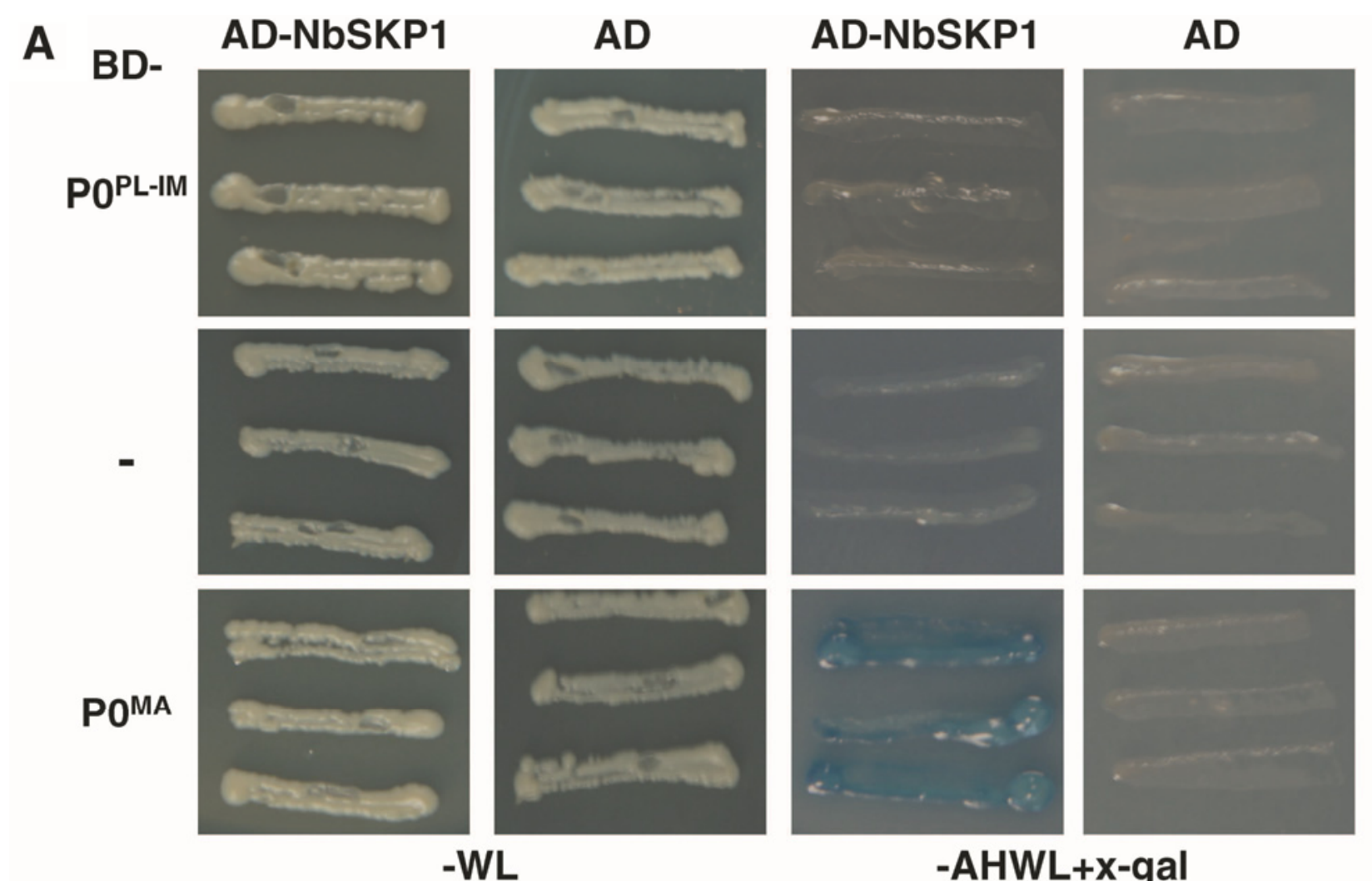

$-A H W L+x-g a l$

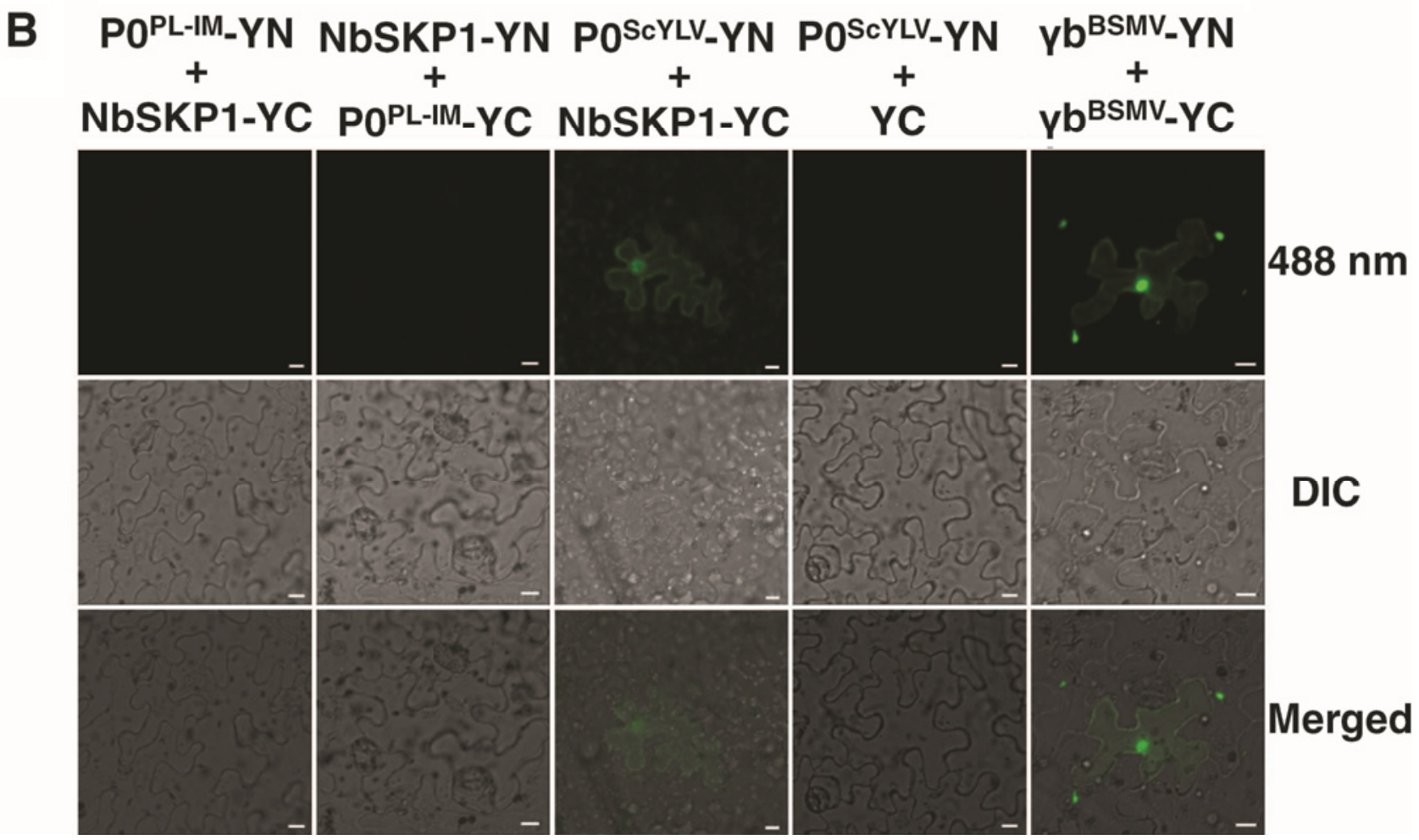

Fig. 6. The $\mathrm{P} 0^{\mathrm{PL}-\mathrm{IM}}$ protein does not interact with Nicotiana benthamiana SKP1 (NbSKP1). A, Interactions of $\mathrm{P} 0^{\mathrm{PL}-\mathrm{IM}}$ and $\mathrm{P} 0^{\mathrm{MA}}$ with $\mathrm{NbSKP} 1$ were investigated by yeast two-hybrid mating experiments using yeast strain $\mathrm{Y} 187$ transformed with $\mathrm{BD}-\mathrm{P0} 0^{\mathrm{PL}-\mathrm{IM}}$ or $\mathrm{P} 0^{\mathrm{MA}}$ and strain $\mathrm{AH} 109$ transformed with $\mathrm{AD}-$ $\mathrm{NbSKP1}$. The yeast strain $\mathrm{Y} 187$ containing $\mathrm{P} 0^{\mathrm{MA}}$ was used as a positive control. Note the $\beta$-galactosidase expression and growth of the positive control (ADNbSKP1 and $\mathrm{BD}-\mathrm{P0} 0^{\mathrm{MA}}$ ) samples and the absence of $\beta$-galactosidase and yeast growth in the other combinations. B, Failure of $\mathrm{P0}{ }^{\mathrm{PL}-\mathrm{IM}}$ to interact with $\mathrm{NbSKP1}$ in bimolecular fluorescence complementation tests. $N$. benthamiana leaves were co-infiltrated for expression of the following combinations of YN-

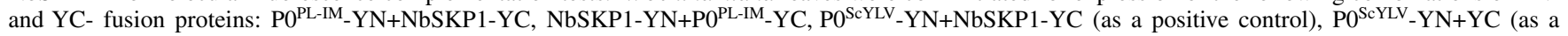
negative control), and $\gamma b-\mathrm{YN}+\gamma \mathrm{b}-\mathrm{YC}$ (as a positive control). Yellow fluorescent protein fluorescence images were recorded at 2 days postinfiltration by visualization at $488 \mathrm{~nm}$, and a differential interference contrast (DIC) image was photographed. Scale bars of all images represent $10 \mu \mathrm{m}$. 


\section{MATERIALS AND METHODS}

Plant material and growth conditions.

All $N$. benthamiana plants were grown in soil at $24 \pm 1^{\circ} \mathrm{C}$ with a photoperiod of $16 \mathrm{~h}$ of light (approximately $7.5 \mu \mathrm{mol} /$ $\left.\mathrm{m}^{2} \cdot \mathrm{s}\right)$ and $8 \mathrm{~h}$ of darkness.

\section{Plasmid constructs.}

The binary expression vectors pGD (Goodin et al. 2002), pGDG, and pGDP19 were obtained from A. O. Jackson at the University of California at Berkeley, U.S.A. The ${ }_{\mathrm{wT}} \mathrm{P} 0^{\mathrm{PL}-\mathrm{IM}}$ and flag-tagged ${ }_{\mathrm{WT}} \mathrm{P} 0^{\mathrm{PL}-\mathrm{IM}}$ constructs used in these experiments were engineered by polymerase chain reaction (PCR) amplified from PLRV (GenBank accession number KC456052) using appropriate specific primers (Table 1). All PCR products were ligated to pMD19-T to obtain pMD19-T-P0 ${ }^{\text {PL-IM }}$ or flagtagged $\mathrm{P} 0^{\mathrm{PL}-\mathrm{IM}}$. The $\mathrm{pMD} 19-\mathrm{T}-\mathrm{P} 0^{\mathrm{PL}-\mathrm{IM}}$ or flag-tagged $\mathrm{P} 0^{\mathrm{PL}-\mathrm{IM}}$ construct was digested with HindIII/BamHI and subcloned into pGD. All mutants were produced by reverse PCR using specific primers, and the $5^{\prime}$ and $3^{\prime}$ primers contained HindIII and BamHI restriction sites (Table 1), respectively. The resulting fragments were inserted into pGD digested with HindIII and BamHI.

\section{Agrobacterium-infiltration and GFP imaging.}

The Agrobacterium tumefaciens GV3101, a gift from D. Baulcombe, was transformed with each plasmid using a freeze- thaw method (Hofgen and Willmitzer 1988). For co-infiltrations, equal volumes of A. tumefaciens cultures (absorbance at $600 \mathrm{~nm}$ $\left[\mathrm{A}_{600}\right]=1.0$ ) harboring the relevant binary plasmids were mixed prior to infiltration, and the fully expanded leaves were injected with a syringe (Voinnet et al. 2000). Leaves were illuminated with a 100-W hand-held long-wave ultraviolet lamp (Black Ray model B 100AP/R; UV Products, Upland, CA U.S.A.) for photography and images were taken with a Nikon 4500 digital camera. All experiments shown in the results were repeated at least three times.

\section{Protein extraction and Western analysis.}

Infiltrated $N$. benthamiana leaves were ground in liquid nitrogen and mixed with $2 \times$ sodium dodecyl sulfate (SDS) sample buffer (100 mM Tris [pH 6.8], 20\% glycerol, 4\% SDS, and $0.2 \%$ bromophenol blue) containing $10 \% \beta$-mercaptoethanol (Laemmli 1970). The samples were then boiled at $100^{\circ} \mathrm{C}$ for 5 $\mathrm{min}$, and centrifuged for $5 \mathrm{~min}$ at $13,000 \times g$ before loading on a gel. To detect GFP expression, proteins were separated by $12.5 \%$ SDS polyacrylamide gel electrophoresis (PAGE) and Western blot analysis was performed by first probing with a rabbit anti-GFP antibody (diluted 1:1,000) and then incubating with anti-rabbit alkaline phosphatase (Sigma, St. Louis). Finally, GFP was detected with the nitro-blue tetrazolium and 5-bromo4-chloro-3-indolyphosphate substrates (Sigma).

For detection of the 6 myc-AtAGO1, $3 \times$ flag ${ }_{w T} \mathrm{P}^{\mathrm{PL}-\mathrm{IM}}$, and $3 \times$ flag mutants of ${ }_{\mathrm{WT}} \mathrm{P} 0^{\mathrm{PL}-\mathrm{IM}}$ in Western blots, proteins were

Table 1. Primer sequences used for polymerase chain reaction

\begin{tabular}{|c|c|}
\hline Primer & Sequence $\left(5^{\prime}\right.$ to $\left.3^{\prime}\right)$ \\
\hline PL71EH-F & CGAATTCAAGCTTATGATTGTATTGACCC \\
\hline PL814B-R & AGGATCCTTATTCTTGTAATTCC \\
\hline PLP03×flag-R & $\begin{array}{l}\text { CGGGATCCTTATTTATCGTCATCGTCTTTGTAGTCTTTATCGTCATCGTCTTTGTAGTCT } \\
\text { TTATCGTCATCGTCTTTGTAGTCACCTCCGCCTTCTTGTAATTCCTTTTGGAG }\end{array}$ \\
\hline PLP0V58I-F & АTTCTCCCTTTGCTCAACTGC \\
\hline PLP0V58A-F & GCTCTCCСТTTGCTCAACTGC \\
\hline PLP0V58-R & ATAAAGAAAAGAGCGGCATATGCGG \\
\hline PLP0S102-F & ATCGTCATTAAACTTGACG \\
\hline PLP0S102P-R & GGTAGGGCCCACGATTTGTATAGC \\
\hline PLP0S102A-R & GGTAGCGCCCACGATTTGTATAG \\
\hline PLP0Y174-F & CATTTGGTTCGGTCTCTATTGG \\
\hline PLP0Y174H-R & CTGATGATTGCCCATAAGGTC \\
\hline PLP0Y174A-R & CTGAGCATTGCCCATAAGGTC \\
\hline PLP0T222A-F & GCACTTACCGGTTTTCCTAT \\
\hline PLP0T222A-R & TCTGAAAGACTTAGCGCGCC \\
\hline PLP0I228V-F & GTTTATGTCCCCTCTGAAGA \\
\hline PLP0I228A-F & GCTTATGTCCCCTCTGAAGA \\
\hline PLP0I228-R & AGGAAAACCGGTAAGTGTTC \\
\hline PLP0LP59AA-F & ATGTTGCCGCTTTGCTCAACTGC \\
\hline PLP0LP59AA-R & AAAGAAAAGAGCGGCATATGCGG \\
\hline PLP0LP76AA-F & CATCCGGCCTTCAAGCTGCGAGGC \\
\hline PLP0LP76AA-R & TTGAAATCCTGCCTCTTTTGCAGTTG \\
\hline PLP0W87A-F & GCGGGATTACTCTGCGGCACC \\
\hline PLP0G88A-F & TGGGCATTACTCTGCGGCACC \\
\hline PLP0WG87AA-F & GCGGCATTACTCTGCGGCACC \\
\hline PLP0WG87GW-F & GGATGGTTACTCTGCGGCACC \\
\hline PLP0WG87AA-R & CTCAAGGCACTCATAGTGGAGG \\
\hline PLP0GW139AA-F & GCTGCGGGACATGACATGGAGGC \\
\hline PLP0G139A-F & GCTTGGGGACATGACATGGAGGC \\
\hline PLP0W140A-F & GGTGCGGGACATGACATGGAGGC \\
\hline PLP0GW139WG-F & TGGGGTGGACATGACATGGAGGC \\
\hline PLP0G141A-F & GGTTGGGCACATGACATGGAGGC \\
\hline PLP0WG140GW-F & GGTGGATGGCATGACATGGAGGC \\
\hline PLP0AWA-F & GCTTGGGCACATGACATGGAGGC \\
\hline PLP0GW139AA-R & GTTTGACAATCCAGCCGCATTTTG \\
\hline PLP0F220R-F & AGTCTCGCAGAACACTTACCGG \\
\hline PLP0F220R-R & TAGCGCGCCCTTGTAGATCAAGC \\
\hline PLP071E-F & CGAATTCATGATTGTATTGACCC \\
\hline PLP0744S-R & GCGTCGACTTATTCTTGTAATTCC \\
\hline PLP0Xba-F & GCTCTAGAATGATTGTATTGACCC \\
\hline PLPOXho-R & CCCTCGAGCAGGTCCTCCTCTGAGATCAGC \\
\hline
\end{tabular}


separated by $7 \%$ SDS-PAGE and probed with an anti-c-myc antibody (1:1,000; Sigma) or an anti-flag antibody $(1: 1,000$; Sigma) followed by an anti-rabbit goat HRP secondary antibody (1:3,000; Bio-Rad, Hercules, CA, U.S.A.). Antibodyprotein interactions were visualized using an enhanced chemiluminescence detection kit (GE Healthcare, Buckinghamshire, U.K.) according to the manufacturer's instructions.

\section{RNA extraction and RNA gel blot analysis.}

Total RNA from agroinfiltrated leaves of $N$. benthamiana was extracted using Trizol reagent (Invitrogen, Carlsbad, CA, U.S.A.). For detection of high-molecular-weight RNA, $5 \mu \mathrm{g}$ of total RNA was separated on $1 \%$ agarose gels. DNA fragments were amplified by PCR and labeled with $\left[\alpha-{ }^{32} \mathrm{P}\right] \mathrm{dCTP}$ using the Prime-a-Gene Labeling System (Promega, Madison, WI, U.S.A.). For detection of small RNAs, $20 \mu \mathrm{g}$ of total RNA was separated on $17 \%$ polyacrylamide- $8 \mathrm{M}$ urea gels. GFP-specific probes were radiolabeled with $\left[\alpha-{ }^{32} \mathrm{P}\right] \mathrm{UTP}$, and hybridizations were performed as described previously (Han et al. 2010).

\section{BiFC assays in $N$. benthamiana leaves}

using confocal laser-scanning microscopy.

For BiFC analysis, the full-length coding sequence of $\mathrm{P} 0^{\mathrm{PL}-\mathrm{IM}}$ was amplified using the PLPOXba-F and PLPOXho-R primers (Table 1) and was cloned into the BiFC vectors pSPYNE-35S and pSPYCE-35S (provided by J. Kudla, Universität Münster) that had been digested with $X b a \mathrm{I}$ and XhoI (Walter et al. 2004). All clones generated by PCR were sequenced completely and the recombinant plasmids were confirmed by restriction analysis. A. tumefaciens EHA105 strains, which contained the two BiFC plasmids and the pGDP19 plasmid, were adjusted to $\mathrm{A}_{600}$ $=1.0$ and co-infiltrated into $N$. benthamiana leaves at a ratio of 0.5:0.5:0.3. Abaxial epidermal cells of infiltrated leaves were assayed for fluorescence at 2 to $3 \mathrm{dpi}$. Fluorescence analysis was performed using a Nikon ECLIPSE TE2000-E inverted fluorescence microscope equipped with a Nikon D-ECLIPSE C1 spectral confocal laser-scanning system. YFP fluorescence was detected at an excitation wavelength of $488 \mathrm{~nm}$ and an emission wavelength of 550 to $590 \mathrm{~nm}$ (Zhang et al. 2011).

\section{Yeast two-hybrid assays.}

The Clontech Matchmaker GAL4 Two-Hybrid System 3 was used to generate yeast strain Y187 containing pGBKT7$\mathrm{P} 0{ }^{\mathrm{PL}-\mathrm{IM}}$ for yeast two-hybrid mating analyses. The P0 ${ }^{\mathrm{PL}-\mathrm{IM}} \mathrm{ORF}$ was amplified with the primers PLP071E-F/PLP0744S-R (Table 1) and the PCR products were ligated to pMD19-T. The clone was then digested with EcoRI and SalI, and the P0 EcoRI/SalI fragments were ligated with EcoRI- and SalIdigested pGBKT7 (Clontech, Mountain View, CA, U.S.A.) to generate $\mathrm{pGBKT7}-\mathrm{P0} \mathrm{PL-IM}^{\mathrm{P}}$ for transformation into strain Y187. Yeast transformations were carried out with a small-scale lithium acetate method. The complementary yeast AH109 mating strain harboring NbSKP1 (GenBank AF494084.1) was previously used in our lab for analysis of interactions of Rice blackstreaked dwarf virus (Wang et al. 2013). Two-hybrid assays were performed as suggested by Clontech. Co-transformants were plated on SD minimal media minus leucine, tryptophan, adenine, and histidine (SD/-Leu/-Trp/-Ade/-His and X-Gal). Positive yeast colonies that could grow on the auxotrophic medium were tested for $\beta$-galactosidase activity and photographed.

\section{ACKNOWLEDGMENTS}

This work was supported by the National Natural Science Foundation of China (31071663) and the Program for Changjiang Scholars and Innovative Research Team in University (IRT1042). We thank A. O. Jackson
(Department of Plant and Microbial Biology, University of California, Berkeley, U.S.A.) for editing the manuscript, H. Guo (Institute of Microbiology, Chinese Academy of Sciences, Beijing) for providing plasmid pCAMBIA-35S-6myc-AGO1, D. Baulcombe (Department of Plant Sciences, University of Cambridge, U.K.) for providing WT and A. tumefaciens GV3101, V. Ziegler-Graff (Institut de Biologie Moléculaire des Plantes du CNRS et de Université Louis Pasteur, 67084 Strasbourg, France) for providing the CABYV infectious plasmid pBin35SCA-WT, and J. Kudla (Institut für Biologie und Biotechnologie der Pflanzen, Universität Münster, Germany) for providing the BiFC vectors pSPYNE-35S and pSPYCE-35S

\section{LITERATURE CITED}

Azevedo, J., Garcia, D., Pontier, D., Ohnesorge, S., Yu, A., Garcia, S., Braun, L., Bergdoll, M., Hakimi, M. A., and Lagrange, T. 2010. Argonaute quenching and global changes in Dicer homeostasis caused by a pathogen-encoded GW repeat protein. Genes Dev. 24:904-915.

Bartel, D. P. 2004. MicroRNAs: Genomics, biogenesis, mechanism, and function. Cell 116:281-297.

Baulcombe, D. 2004. RNA silencing in plants. Nature 431:356-363.

Baumberger, N., and Baulcombe, D. 2005. Arabidopsis ARGONAUTE1 is an RNA Slicer that selectively recruits microRNAs and short interfering RNAs. Proc. Natl. Acad. Sci. U.S.A. 102:11928-11933.

Baumberger, N., Tsai, C. H., Lie, M., Havecker, E., and Baulcombe, D. C. 2007. The polerovirus silencing suppressor P0 targets ARGONAUTE proteins for degradation. Curr. Biol. 17:1609-1614.

Bortolamiol, D., Pazhouhandeh, M., Marrocco, K., Genschik, P., and Ziegler-Graff, V. 2007. The polerovirus F box protein P0 targets ARGONAUTE1 to suppress RNA silencing. Curr. Biol. 17:1615-1621.

Burgyán, J., and Havelda, Z. 2011. Viral suppressors of RNA silencing. Trends Plant Sci. 16:265-272.

Csorba, T., Bovi, A., Dalmay, T., and Burgyán, J. 2007. The p122 subunit of Tobacco mosaic virus replicase is a potent silencing suppressor and compromises both small interfering RNA- and microRNA-mediated pathways. J. Virol. 81:11768-11780.

Csorba, T., Pantaleow, V., and Burgyán, J. 2009. RNA silencing: An antiviral mechanism. Adv. Virus Res. 75:35-71.

Csorba, T., Lózsa, R., Hutvágner, G., and Burgyán, J. 2010. Polerovirus protein $\mathrm{P} 0$ prevents the assembly of small RNA-containing RISC complexes and leads to degradation of ARGONAUTE1. Plant J. 62:463472.

Deleris, A., Gallego-Bartolome, J., Bao, J., Kasschau, K. D., Carrington, J. C., and Voinnet, O. 2006. Hierarchical action and inhibition of plant Dicer-like proteins in antiviral defense. Science 313:68-71.

Delfosse, V. C., Agrofoglio, Y. C., Casse, M. F., Kresic, I. B., Hopp, H. E., Ziegler-Graff, V., and Distéfano, A. J. 2013. The P0 protein encoded by cotton leafroll dwarf virus (CLRDV) inhibits local but not systemic RNA silencing. Virus Res. 180:70-75.

Derrien, B., Baumberger, N., Schepetilnikov, M., Viotti, C., De Cillia, J., Ziegler-Graff, V., Isono, E., Schumacher, K., and Genschik, P. 2012. Degradation of the antiviral component ARGONAUTE1 by the autophagy pathway. Proc. Natl. Acad. Sci. U.S.A. 109:15942-15946.

Ding, S. W. 2010. RNA-based antiviral immunity. Nat. Rev. Immunol. 10:632-644.

Ding, S. W., and Voinnet, O. 2007. Antiviral immunity directed by small RNAs. Cell 130:413-426.

Duan, C.-G., Fang, Y.-Y., Zhou, B.-J., Zhao, J.-H., Hou, W.-N., Zhu, H., Ding, S.-W., and Guo, H.-S. 2012. Suppression of Arabidopsis ARGONAUTE1-mediated slicing, transgene-induced RNA silencing, and DNA methylation by distinct domains of the Cucumber mosaic virus $2 \mathrm{~b}$ protein. Plant Cell 24:259-274.

Elbashir, S. M., Martinez, J., Patkaniowska, A., Lendeckel, W., and Tuschl, T. 2001. Functional anatomy of siRNAs for mediating efficient RNAi in Drosophila melanogaster embryo lysate. EMBO (Eur. Mol. Biol. Organ.) J. 20:6877-6888.

Farrás, R., Ferrando, A., Jásik, J., Kleinow, T., Ökrész, L., Tiburcio, A. Salchert, K., Del Pozo, C., Schell, J., and Koncz, C. 2001. SKP1-SnRK protein kinase interactions mediate proteasomal binding of a plant SCF ubiquitin ligase. EMBO (Eur. Mol. Biol. Organ.) J. 20:2742-2756.

Fusaro, A. F., Correa, R. L., Nakasugi, K., Jackson, C., Kawchuk, L., Vaslin, M. F. S., and Waterhouse, P. M. 2012. The Enamovirus P0 protein is a silencing suppressor which inhibits local and systemic RNA silencing through AGO1 degradation. Virology 426:178-187.

Gagne, J. M., Downes, B. P., Shiu, S. H., Durski, A. M., and Vierstra, R. D. 2002. The F-box subunit of the SCF E3 complex is encoded by a diverse superfamily of genes in Arabidopsis. Proc. Natl. Acad. Sci. U.S.A. 99:11519-11524.

Giner, A., Lakatos, L., García-Chapa, M., López-Moya, J. J., and Burgyán, 
J. 2010. Viral protein inhibits RISC activity by argonaute binding through conserved WG/GW motifs. PLoS Pathog. 6:e1000996.

González, I., Martínez, L., Rakitina, D. V., Lewsey, M. G., Atencio, F. A., Llave, C., Kalinina, N. O., Carr, J. P., Palukaitis, P., and Canto, T. 2010. Cucumber mosaic virus $2 \mathrm{~b}$ protein subcellular targets and interactions: Their significance to RNA silencing suppressor activity. Mol. PlantMicrobe Interact. 23:294-303.

Goodin, M. M., Dietzgen, R. G., Schichnes, D., Ruzin, S., and Jackson, A. O. 2002. pGD vectors: Versatile tools for the expression of green and red fluorescent protein fusions in agroinfiltrated plant leaves. Plant J. 31:375-383.

Goto, K., Kobori, T., Kosaka, Y., Natsuaki, T., and Masuta, C. 2007. Characterization of silencing suppressor $2 \mathrm{~b}$ of Cucumber mosaic virus based on examination of its small RNA-binding abilities. Plant Cell Physiol. 48:1050-1060.

Guilley, H., Bortolamiol, D., Jonard, G., Bouzoubaa, S., and Ziegler-Graff, V. 2009. Rapid screening of RNA silencing suppressors by using a recombinant virus derived from Beet necrotic yellow vein virus. J. Gen. Virol. 90:2536-2541.

Hamera, S., Song, X., Su, L., Chen, X., and Fang, R. 2012. Cucumber mosaic virus suppressor $2 \mathrm{~b}$ binds to AGO4-related small RNAs and impairs AGO4 activities. Plant J. 69:104-115.

Hamilton, A. J., and Baulcombe, D. C. 1999. A species of small antisense RNA in posttranscriptional gene silencing in plants. Science 286:950952.

Han, Y. H., Xiang, H. Y., Wang, Q., Li, Y. Y., Wu, W. Q., Han, C. G., Li, D. W., and Yu, J. L. 2010. Ring structure amino acids affect the suppressor activity of Melon aphid-borne yellows virus P0 protein. Virology 406:21-27.

Hofgen, R., and Willmitzer, L. 1988. Storage of competent cells for Agrobacterium transformation. Nucleic Acids Res. 16:9877-9877.

Hutvagner, G., and Simard, M. J. 2008. Argonaute proteins: Key players in RNA silencing. Nat. Rev. Mol. Cell Biol. 9:22-32.

Jin, H., and Zhu, J. K. 2010. A viral suppressor protein inhibits host RNA silencing by hooking up with Argonautes. Genes Dev. 24:853-856.

Johansen, L. K., and Carrington, J. C. 2001. Silencing on the spot. Induction and suppression of RNA silencing in the Agrobacterium-mediated transient expression system. Plant Physiol. 126:930-938.

King, A. M. Q., Adams, M. J., Eric B. Carstens, and Lefkowitz, E. J. 2011 Virus taxonomy. In: Ninth Rep. Int. Committee on Taxonomy of Viruses. Elsevier Inc., San Diego, CA, U.S.A.

Kozlowska-Makulska, A., Guilley, H., Szyndel, M. S., Beuve, M., Lemaire, O., Herrbach, E., and Bouzoubaa, S. 2010. P0 proteins of European beet-infecting poleroviruses display variable RNA silencing suppression activity. J. Gen. Virol. 91:1082-1091.

Laemmli, U. K. 1970. Cleavage of structural proteins during the assembly of the head of bacteriophage T4. Nature 227:680-685.

Lakatos, L., Csorba, T., Pantaleo, V., Chapman, E. J., Carrington, J. C., Liu, Y. P., Dolja, V. V., Calvino, L. F., López-Moya, J. J., and Burgyán, J. 2006. Small RNA binding is a common strategy to suppress RNA silencing by several viral suppressors. EMBO (Eur. Mol. Biol. Organ.) J. 25:2768-2780.

Li, Y., Lu, J., Han, Y., Fan, X., and Ding, S.-W. 2013. RNA interference functions as an antiviral immunity mechanism in mammals. Science 342:231-234.

Lindbo, J. A., and Dougherty, W. G. 2005. Plant pathology and RNAi: A brief history. Annu. Rev. Phytopathol. 43:191-204.

Liu, Y., Zhai, H., Zhao, K., Wu, B., and Wang, X. 2012. Two suppressors of RNA silencing encoded by cereal-infecting members of the family Luteoviridae. J. Gen. Virol. 93:1825-1830.

Maillard, P., Ciaudo, C., Marchais, A., Li, Y., Jay, F., Ding, S., and Voinnet, O. 2013. Antiviral RNA interference in mammalian cells. Science 342:235-238

Mangwende, T., Wang, M. L., Borth, W., Hu, J., Moore, P. H., Mirkov, T. E., and Albert, H. H. 2009. The P0 gene of Sugarcane yellow leaf virus encodes an RNA silencing suppressor with unique activities. Virology
384:38-50.

Mérai, Z., Kerényi, Z., Kertész, S., Magna, M., Lakatos, L., and Silhavy, D. 2006. Double-stranded RNA binding may be a general plant RNA viral strategy to suppress RNA silencing. J. Virol. 80:5747-5756.

Mi, S., Cai, T., Hu, Y., Chen, Y., Hodges, E., Ni, F., Wu, L., Li, S., Zhou, H., and Long, C. 2008. Sorting of small RNAs into Arabidopsis Argonaute complexes is directed by the $5^{\prime}$ terminal nucleotide. Cell 133:116127.

Napoli, C., Lemieux, C., and Jorgensen, R. 1990. Introduction of a chimeric chalcone synthase gene into petunia results in reversible co-suppression of homologous genes in trans. Plant Cell 2:279-289.

Pazhouhandeh, M. 2007. The mechanism of action of polerovirus P0 in RNA silencing suppression. Doctoral dissertation, University of Louis Pasteur, Strasbourg, France.

Pazhouhandeh, M., Dieterle, M., Marrocco, K., Lechner, E., Berry, B., Brault, V., Hemmer, O., Kretsch, T., Richards, K. E., and Genschik, P. 2006. F-box-like domain in the polerovirus protein P0 is required for silencing suppressor function. Proc. Natl. Acad. Sci. U.S.A. 103:19941999.

Pfeffer, S., Dunoyer, P., Heim, F., Richards, K., Jonard, G., and ZieglerGraff, V. 2002. P0 of Beet western yellows virus is a suppressor of posttranscriptional gene silencing. J. Virol. 76:6815-6824.

Qi, Y., Denli, A. M., and Hannon, G. J. 2005. Biochemical Specialization within Arabidopsis RNA Silencing Pathways. Mol. Cell 19:421-428.

Risseeuw, E. P., Daskalchuk, T. E., Banks, T. W., Liu, E., Cotelesage, J., Hellmann, H., Estelle, M., Somers, D. E., and Crosby, W. L. 2003. Protein interaction analysis of SCF ubiquitin E3 ligase subunits from Arabidopsis. Plant J. 34:753-767.

Ruiz, M. T., Voinnet, O., and Baulcombe, D. C. 1998. Initiation and maintenance of virus-induced gene silencing. Plant Cell 10:937-946.

Sadowy, E., Maasen, A., Juszczuk, M., David, C., Zagórski-Ostoja, W., Gronenborn, B., and Hulanicka, M. D. 2001. The ORF0 product of Potato leafroll virus is indispensable for virus accumulation. J. Gen. Virol. 82:1529-1532.

Silhavy, D., and Burgyán, J. 2004. Effects and side-effects of viral RNA silencing suppressors on short RNAs. Trends Plant Sci. 9:76-83.

Szabó, E. Z., Manczinger, M., Göblös, A., Kemény, L., and Lakatos, L. 2012. Switching on RNA silencing suppressor activity by restoring Argonaute binding to a viral protein. J. Virol. 86:8324-8327.

Vaucheret, H. 2008. Plant Argonautes. Trends Plant Sci. 13:350-358.

Voinnet, O. 2005. Induction and suppression of RNA silencing: Insights from viral infections. Nat. Rev. Genet. 6:206-220.

Voinnet, O., Lederer, C., and Baulcombe, D. C. 2000. A viral movement protein prevents spread of the gene silencing signal in Nicotiana benthamiana. Cell 103:157-167.

Walter, M., Chaban, C., Schütze, K., Batistic, O., Weckermann, K., Näke, C., Blazevic, D., Grefen, C., Schumacher, K., and Oecking, C. 2004 Visualization of protein interactions in living plant cells using bimolecular fluorescence complementation. Plant J. 40:428-438.

Wang, M. B., Masuta, C., Smith, N. A., and Shimura, H. 2012. RNA silencing and plant viral diseases. Mol. Plant-Microbe Interact. 25:12751285

Wang, Q., Tao, T., Han, Y., Chen, X., Fan, Z., Li, D., Yu, J., and Han, C. 2013. Nonstructural protein P7-2 encoded by Rice black-streaked dwarf virus interacts with SKP1, a core subunit of SCF ubiquitin ligase. Virol. J. 10:325-336.

Zarghani, S. N., Shams-Bakhsh, M., Zand, N., Sokhandan-Bashir, N., and Pazhouhandeh, M. 2012. Genetic analysis of Iranian population of Potato leafroll virus based on ORF0. Virus Genes 45:567-574.

Zhang, X., Yuan, Y. R., Pei, Y., Lin, S. S., Tuschl, T., Patel, D. J., and Chua, N. H. 2006. Cucumber mosaic virus-encoded $2 \mathrm{~b}$ suppressor inhibits Arabidopsis Argonaute1 cleavage activity to counter plant defense. Genes Dev. 20:3255-3268.

Zhang, Y., Zhang, X., Niu, S., Han, C., Yu, J., and Li, D. 2011. Nuclear localization of Beet black scorch virus capsid protein and its interaction with importin $\alpha$. Virus Res. 155:307-315. 